\title{
Separation of Non-Hazardous, Non-Radioactive Components from ICPP Calcine via Chlorination
}

Lee O. Nelson

Published May 1995

Idaho National Engineering Laboratory High Level Waste Immobilization Department

Lockheed Idaho Technologies Company Idaho Falls, Idaho 83415

Prepared for the

U.S. Department of Energy

Assistant Secretary for Environmental Management

Under DOE Idaho Operations Office

Contract DE-AC07-94ID13223 


\section{DISCLAIMER}

Portions of this document may be illegible electronic image products. Images are produced from the best available original document. 


\begin{abstract}
A pyrochemical treatment method for separating non-radioactive from radioactive components in solid granular waste accumulated at the Idaho Chemical Processing Plant was investigated. The goal of this study was to obtain kinetic and chemical separation data on the reaction products of the chlorination of the solid waste, known as calcine. Thermodynamic equilibrium calculations were completed to verify that a separation of radioactive and nonradioactive calcine components was possible. Bench-scale chlorination experiments were completed subsequently in a variety of reactor configurations including: a fixed-bed reactor (reactive gases flowed around and not through the particle bed), a packed/fluidized-bed reactor, and a packed-bed reactor (reactive gases flowed through the particle bed). Chemical analysis of the reaction products generated during the chlorination experiments verified the predictions made by the equilibrium calculations. An empirical first-order kinetic rate expression was developed for each of the reactor configurations.
\end{abstract}

\title{
DISCLAIMER
}

This report was prepared as an account of work sponsored by an agency of the United States Government. Neither the United States Government nor any agency thereof, nor any of their employees, makes any warranty, express or implied, or assumes any legal liability or responsibility for the accuracy, completeness, or usefulness of any information, apparatus, product, or process disclosed, or represents that its use would not infringe privately owned rights. Reference herein to any specific commercial product, process, or service by trade name, trademark, manufacturer, or otherwise does not necessarily constitute or imply its endorsement, recommendation, or favoring by the United States Government or any agency thereof. The views and opinions of authors expressed herein do not necessarily state or reflect those of the United States Government or any agency thereof. 



\section{ACKNOWLEDGMENTS}

The author would like to acknowledge the following people for assistance in the completion of this thesis. Rich Tillotson provided excellent support in completing several of the chlorination experiments. Gary Gregston assisted in the design and fabrication of all experimental reactors. Gary's glass blowing expertise permitted testing a variety of experimental reactors. The analytical chemistry department at the ICPP and Del Miley in the SEM lab at the IRC provided excellent analyses. Funding for this work was provided by the Department of Energy Office of Technology Development. 



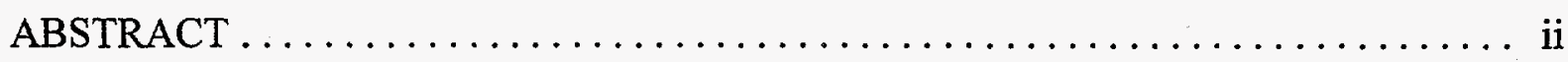

ACKNOWLEDGMENTS $\ldots \ldots \ldots \ldots \ldots \ldots \ldots \ldots \ldots \ldots \ldots \ldots \ldots \ldots$ iii

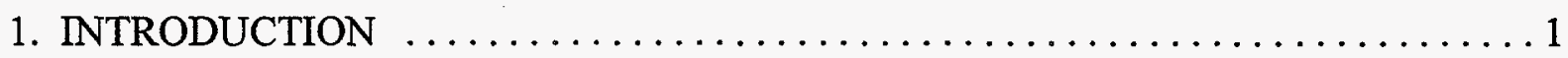

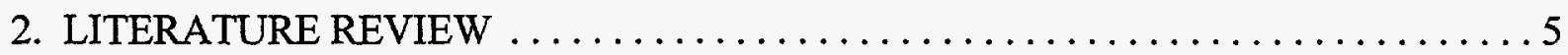

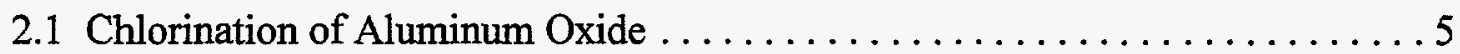

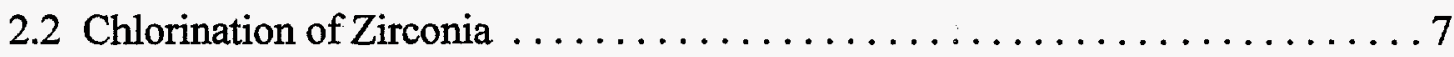

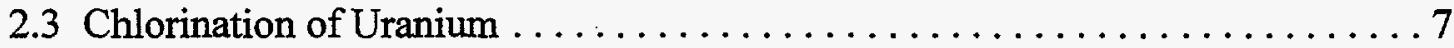

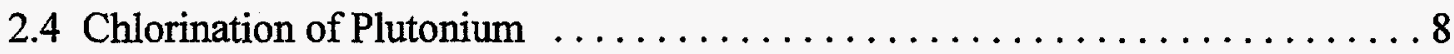

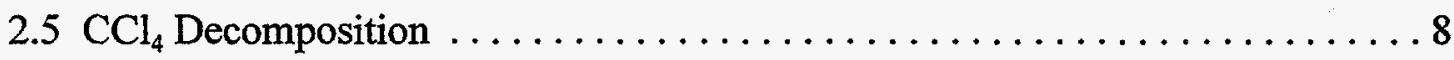

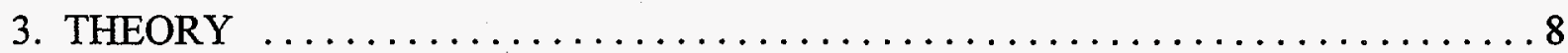

3.1 Thermodynamic Equilibrium $\ldots \ldots \ldots \ldots \ldots \ldots \ldots \ldots \ldots \ldots \ldots$

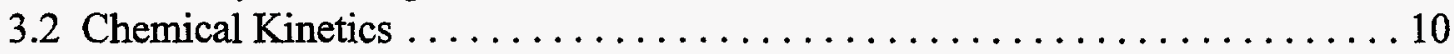

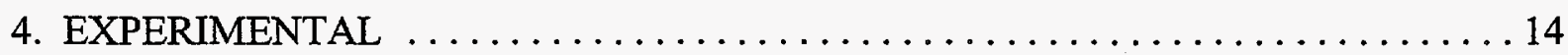

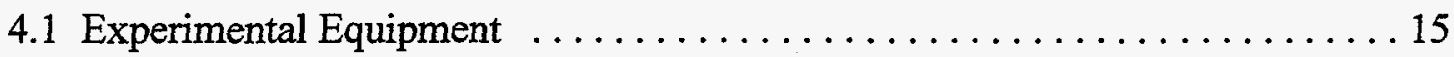

4.2 Experimental Materials and Procedure. . . . . . . . . . . . . . . . . 19

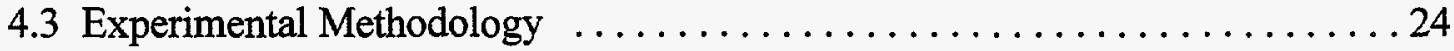

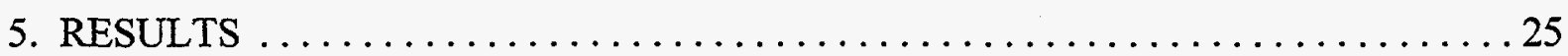

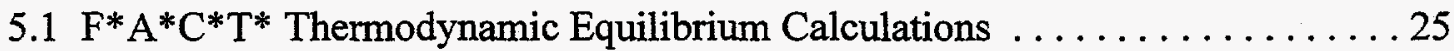

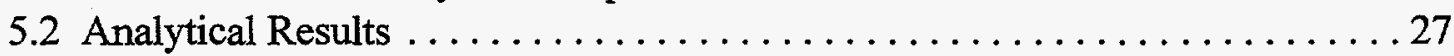

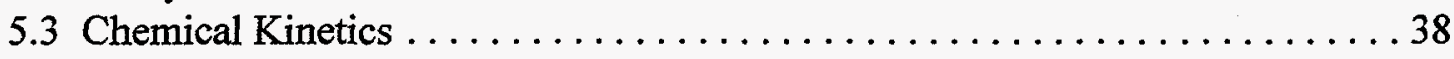

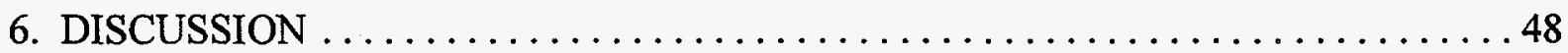

6.1 Thermodynamic Equilibrium Calculations $\ldots \ldots \ldots \ldots \ldots \ldots \ldots \ldots . \ldots 48$

6.2 Alumina Calcine Chlorination Kinetics ................... $51^{\text {st }}$

6.3 Alumina Calcine Chlorination Reaction Mechanisms and Kinetic Model. .... 53

7. CONCLUSIONS AND RECOMMENDATIONS $\ldots \ldots \ldots \ldots \ldots \ldots \ldots \ldots$

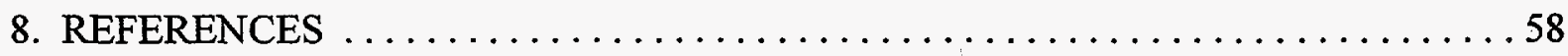




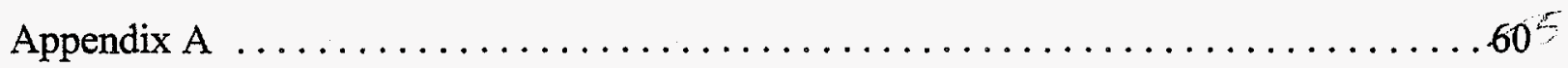

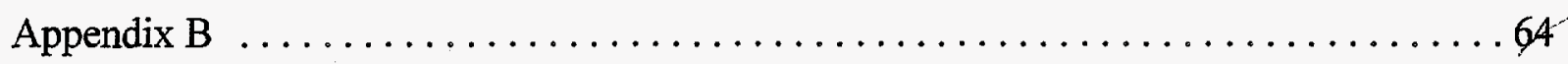




\section{List of Tables}

Table 1 Representative Chemical Composition and Relative Volumes of ICPP Calcined

Wastes

Table 2 Activation Energy for Four Aluminum Oxide-Chlorine Reactions $\ldots \ldots \ldots \ldots 6$

Table 3 Activation Energy for Two Zirconia-Chlorine Reactions $\ldots \ldots \ldots \ldots \ldots \ldots \ldots 7$

Table 4 Compound Behavior in Chloride Volatility Process $\therefore \ldots \ldots \ldots \ldots \ldots \ldots$

Table 5 Normalized Oxide Composition of Run 77 and Run 80 Pilot-Plant Calcine . . . 19

Table 6 X-Ray Diffraction Analysis of $\mathrm{CaCl}_{2}$-Washed Zirconia Calcine $\ldots \ldots \ldots \ldots 23$

Table 7 Calculated Chemical Composition of Alumina and Zirconia Calcine

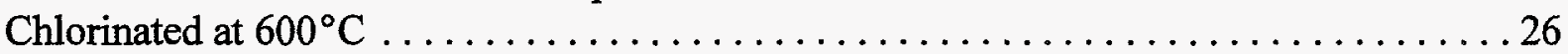

Table 8 EDS Analysis of Residual Solids from Chlorinated Zirconia Calcine ... . . . 30

Table 9 X-Ray Diffraction Analysis of Zirconia Calcine $\ldots \ldots \ldots \ldots \ldots \ldots$

Table 10 Mercury Porosymmetry of Zirconia Calcine Before and After Chlorination . . . 31

Table 11 SEM and EDS Analysis of Residual Calcine from Alumina

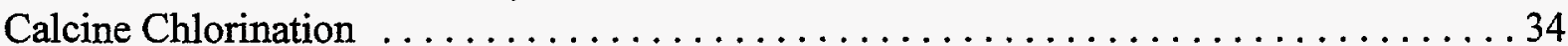

Table 12 X-Ray Diffraction Analysis of Unreacted and Chlorinated Alumina Calcine . . . 35

Table 13 Mercury Porosymmetry of Alumina Pilot-Plant Calcine Before and After Chlorination

Table 14 Elemental Analysis of Off-Gas and Residual Solid Samples Taken During Chlorination of Non-Radioactive Alumina Calcine $\ldots \ldots \ldots \ldots \ldots \ldots \ldots \ldots \ldots$

Table 15 Analytical Results from Radioactive Calcine Chlorination Tests . . . . . . . 37

Table 16 Observed Mass Loss of Chlorinated Alumina and Zirconia Calcine ... . . . 39

Table 17 Experimental Conditions Used in Statistically-Designed Calcine Chlorination

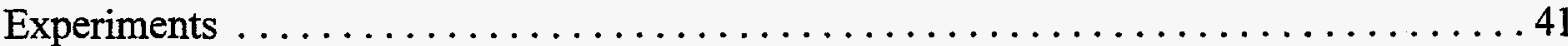


Table 18 Mass Change ofAlumina Calcine during Chlorination in a Packed Bed Reactor

Table 19 Mass Change Observed During Calcine Chlorination Experiments of Actual Radioactive Calcine

Table A.1 Experimental Raw Data from Calcine Chlorination Experiments Completed in a Packed/Fluidized Bed Reactor 60

Table B.1 Experimental Raw Data from Calcine Chlorination Experiments Completed in a Packed Bed Reactor 


\section{List of Figures}

Figure 1. Schematic diagram of the proposed pyrochemical process for treating accumulated

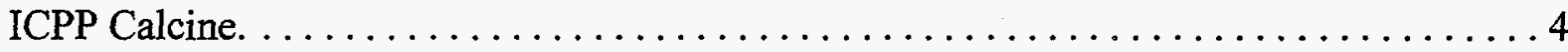

Figure 2. Schematic diagram of the (a) constant particle volume and the (b) shrinking core heterogeneous chemical kinetic models.

Figure 3. Schematic diagram of a solid particle undergoing chemical reaction with a gas.

Figure 4. Diagram of the fixed-bed reactor configuration used to study the feasibility of calcine chlorination.

Figure 5. Diagram of the packed/fluidized-bed reactor configuration used to test the feasibility of calcine chlorination.

Figure 6. Diagram of the packed-bed reactor configuration used to test the feasibility of calcine chlorination.

Figure 7. $\mathrm{CCl}_{4}$ delivery system used in calcine chlorination experiments.

Figure 8. SEM photographs of unreacted zirconia and chlorinated zirconia pilot-plant calcine. a) Photograph of zirconia calcine before chlorination (50x). b) Photograph of

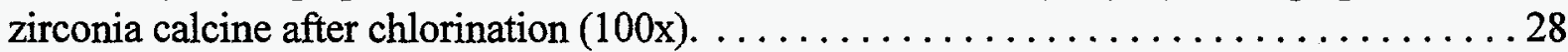

Figure 9. SEM elemental map of chlorinated zirconia pilot-plant calcine.

Figure 10. SEM photographs of chlorinated alumina pilot-plant calcine and condensed volatile species; a) Photograph before chlorination (300x), b) Photograph after chlorination $(200 \mathrm{x})$, and $\mathrm{c})$ Photograph of condensed volatile species generated during chlorination $(1000 \mathrm{x})$.

Figure 11. Measured residual mass of Run 77 (alumina) calcine during chlorination with a $\mathrm{CO}-\mathrm{Cl}_{2}$ mixture at $600^{\circ} \mathrm{C}$.

Figure 12. Conversion of calcine by chlorination with $\mathrm{CCl}_{4}$ at $500^{\circ} \mathrm{C}$ in a packed/fluidized-

bed reactor setup.

Figure 13. Reaction rate constant for the reaction of alumina calcine with $\mathrm{CCl}_{4}$ at various temperatures.

Figure 14. Conversion of calcine by chlorination with $\mathrm{CCl}_{4}$ at $600^{\circ} \mathrm{C}$ in a packed/fluidizedbed reactor. . . . . . . . . . . . . . . . . . . . . . . . . . . . 44 
Figure 15. Conversion of calcine by chlorination with $\mathrm{CCl}_{4}$ at $600^{\circ} \mathrm{C}$ in a packed-bed reactor

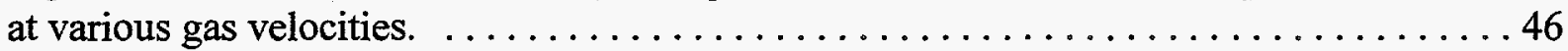

Figure 16. Alumina calcine conversion observed during experiments completed in a packed-

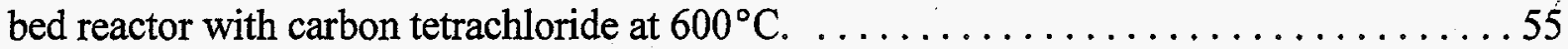




\section{INTRODUCTION}

A significant effort is currently being expended within the Department of Energy (DOE) to develop methods to treat and dispose of Idaho Chemical Processing Plant (ICPP) high-level waste ( $\mathrm{HLW}$ ) accumulated from spent nuclear fuel reprocessing and plant decontamination activities. Since 1963, the liquid HLW accumulated at the ICPP has been solidified to a granular material (calcine) in a fluidized-bed calciner. Currently, about $3,900 \mathrm{~m}^{3}$ of calcine are stored at the ICPP in underground, concrete-encased, stainless-steel bins.

The chemical composition of the calcine varies within each bin, but may be categorized into four general types: 1) alumina, 2) zirconia, 3) zirconia-sodium, and 4) fluorinel-sodium. ${ }^{1}$ The chemical composition of these four major calcine types is shown in Table 1. The compositions shown in Table 1 are based on the assumption that all fluoride is tied up with calcium, and all other metals ( $\mathrm{Al}, \mathrm{Zr}, \mathrm{Na}$, etc.) are oxides. In reality, the composition of calcine is more complex. The principal calcine components are aluminum oxide, calcium fluoride, calcium oxide, and zirconium dioxide. The radioactive calcine components represent less than $1.0 \mathrm{wt} \%$ of the calcine mass.

Calcine was originally intended to be a long-term intermediate waste form. However, radioactive components of calcine calcine are leachable in water and therefore, calcine is not a suitable form for final disposal. As a result, a research and development program is currently underway to develop feasible and cost-effective processing and immobilization schemes to treat and dispose of calcine. The immobilization alternatives currently under consideration for the calcine include formation of glass or glass-ceramic waste form. Both alternatives involve heating a calcine/additive mixture to 1050 to $1200^{\circ} \mathrm{C}$ (and simultaneously applying 10 to $20 \mathrm{ksi}$ for the glass-ceramic process) to form a leach-resistant monolith which would be disposed of in a repository. 
Table 1

Representative Chemical Composition and

Relative Volumes of ICPP Calcined Wastes

\begin{tabular}{|c|c|c|c|c|}
\hline Component & Alumina & Zirconia & $\begin{array}{c}\text { Fluorinel-Na } \\
\text { Blend 4.2:1 }\end{array}$ & Ziconia-Na Blend \\
\hline $\mathrm{Al}_{2} \mathrm{O}_{3}$ & 90.6 & 14.4 & 9.6 & 14.1 \\
\hline $\mathrm{ZrO}_{2}$ & $\ldots$ & 23.4 & 17.5 & 19.0 \\
\hline $\mathrm{CaF}_{2}$ & - & 54.3 & 42.4 & 44.4 \\
\hline $\mathrm{B}_{2} \mathrm{O}_{3}$ & 0.6 & 3.0 & 2.9 & 2.5 \\
\hline $\mathrm{CdO}$ & -- & -- & 5.7 & -- \\
\hline $\mathrm{Na}_{2} \mathrm{O}$ & 3.1 & -- & 5.1 & 4.5 \\
\hline $\mathrm{K}_{2} \mathrm{O}$ & -- & -- & 1.1 & 0.9 \\
\hline $\mathrm{CaO}$ & -- & 3.9 & 12.2 & 12.8 \\
\hline $\mathrm{Fe}_{2} \mathrm{O}_{3}$ & 0.6 & 0.1 & 0.2 & 0.3 \\
\hline $\mathrm{Hg}$ & 2.9 & -- & -- & -- \\
\hline $\mathrm{SO}_{4}$ & 1.2 & -- & 2.6 & 0.3 \\
\hline $\mathrm{PO}_{4}$ & -- & $\cdots$ & 0.2 & 0.2 \\
\hline Other & -- & 1.0 & 1.0 & 1.0 \\
\hline Volatiles & 1 & 1.0 & $5-10$ & $3-8$ \\
\hline Radionuclides & $<1.0$ & $<1.0$ & $<1.0$ & $<1.0$ \\
\hline $\begin{array}{l}\text { Volume in Bin Sets } \\
\qquad\left(\mathrm{m}^{3}\right)^{*}\end{array}$ & 765 & 1244 & 150 & 1400 \\
\hline
\end{tabular}

An additional $300 \mathrm{~m}^{3}$ of 3-way blend calcine (a blend of aluminum, sodium, and fluorinel liquid waste) were generated in campaign $\mathrm{H} 3$

It has been postulated that a reduction in disposal costs would be realized if the hazardous and radioactive calcine components could be separated from the remaining calcine components prior to immobilization and disposal. Two separation schemes are currently being studied as part of the ICPP research and development program: 1) a series of 
pyrochemical (high-temperature, non-aqueous) separations followed by vitrification of the radioactive waste streams and 2) a series of aqueous separations followed by vitrification of the radioactive waste streams. Each separation process has the potential to save 90 to $95 \%$ of the expected HLW immobilization and disposal costs. Therefore, development and implementation of an aqueous or pyrochemical separations process is economically attractive.

The purpose of this work was to investigate the feasibility of separating non-radioactive from radioactive calcine components via chlorination as part of the pyrochemical process development program. A schematic diagram of the proposed pyrochemical process flow sheet is shown in Figure 1. The main processing steps are: 1) calcine stabilization at $600^{\circ} \mathrm{C}$ to decompose nitrate salts, volatilize adsorbed $\mathrm{CO}_{x}$, and flash residual $\mathrm{H}_{2} \mathrm{O}, 2$ ) heat treatment of the calcine at $\sim 1000^{\circ} \mathrm{C}$ to volatilize $\mathrm{Cs}$ and possibly $\mathrm{Cd}, 3$ ) chlorination of the calcine followed by separation of volatile chlorides (mainly non-radioactive) from the solid nonvolatile oxide and chloride residue, 4) direct reduction of the solid residue to a metallic phase, 5) metal/salt separation, and 6) HLW immobilization and disposal. This work relates to Step Number 3, calcine chlorination. 


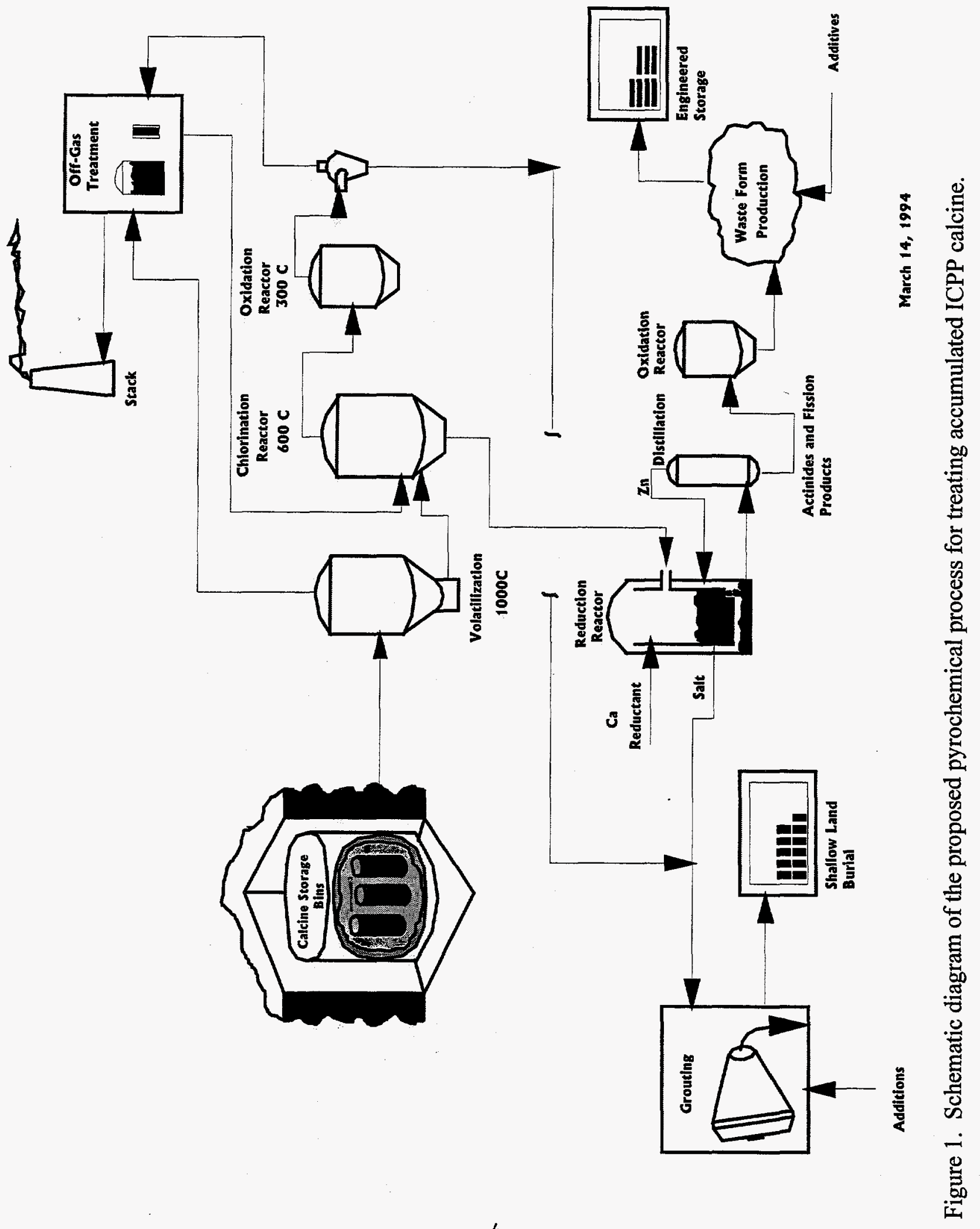




\section{LITERATURE SEARCH}

Calcine consists of a mixture of metal oxides and, except for alumina calcine, fluoride salts. Several high-temperature unit operations have been identified to segregate the nonhazardous, hazardous, and radioactive calcine components. For example, a simple operation is to heat calcine to $600^{\circ} \mathrm{C}$ in air to decompose nitrate salts and remove $90 \%$ of the nitrogen as $\mathrm{NO}_{\mathrm{x}}$. Over $99 \%$ of the ${ }^{137} \mathrm{Cs}$ and $70 \%$ of the $\mathrm{Cd}$ are removed as calcine is heated to over $1000^{\circ} \mathrm{C}$. Trace quantities of $\mathrm{Cs}$ and $\mathrm{Cd}$ volatilize from the calcine at temperatures as low as $600^{\circ} \mathrm{C}$. However, efficient removal of $\mathrm{Cs}$ and $\mathrm{Cd}$ is not realized below temperatures of $1000^{\circ} \mathrm{C}$. Other calcine components such as Tc $\left(50 \mathrm{wt} \%\right.$ volatilizes in 30 minutes at $\left.600^{\circ} \mathrm{C}\right)$, $\mathrm{Na}$, and $\mathrm{Ru}$ may volatilize at temperatures greater than $1000^{\circ} \mathrm{C}$, but no data specific to calcine are available. Actinide elements are not expected to volatilize during calcine heat treatment at $1000^{\circ} \mathrm{C}^{2}$

A more complicated high-temperature separations process identified involves reacting calcine with chlorine and a reducing agent such as $\mathrm{CO}-\mathrm{Cl}_{2}$ or $\mathrm{CCl}_{4}$. A separation would be observed as non-volatile oxides such as $\mathrm{Al}_{2} \mathrm{O}_{3}, \mathrm{~B}_{2} \mathrm{O}_{3}$, and $\mathrm{ZrO}_{2}$ are converted to volatile chlorides. This separations process is called chloride volatility. Chloride volatility has been used or studied for use in several separation schemes such as purification and separation of $\mathrm{Ti}, \mathrm{Al}, \mathrm{Zr}, \mathrm{Mo}, \mathrm{Fe}, \mathrm{U}$, and $\mathrm{Pu}$ metals from impurities. Those of particular interest to this study are investigations involving $\mathrm{Al}, \mathrm{Zr}, \mathrm{U}$, and $\mathrm{Pu}$ as these elements are found in ICPP calcine. Chlorination of other metals found in ICPP calcine were not identified in the literature.

\subsection{Chlorination of Aluminum Oxide}

The current industrial application of alumina chlorination is in the preparation of reagentgrade $\mathrm{AlCl}_{3} \cdot{ }^{3-6}$ Chlorination of bauxite ores (see Reference 3) was investigated as a method to separate aluminum from impurities such as iron oxide (6-8wt\%) and lesser quantities of 
titanium and silicon. Bauxite ore samples were heat treated at $1050^{\circ} \mathrm{C}$ in air to remove water and to ensure formation of low density $\gamma$-alumina. Heat treatment of the ore at temperatures in excess of $1050^{\circ} \mathrm{C}$ produced high density (non-reactive) $\alpha$-alumina. Heat-treated samples were pressed to $90 \%$ of theoretical density to prepare sample pellets for this study. Both CO$\mathrm{Cl}_{2}$ and $\mathrm{CCl}_{4}$, diluted in argon were used as chlorinating reagents.

The reaction rate observed during chlorination of pure alumina samples at temperatures between 300 and $600^{\circ} \mathrm{C}$ showed a clear Arrhenius-type dependence (see Reference 4). The fastest chlorination rates were observed at temperatures between 600 and $700^{\circ} \mathrm{C}$. No increase in reaction rate was observed at temperatures between 700 and $1050^{\circ} \mathrm{C}$. The lack of reaction rate temperature dependance was attributed to: 1) reduction in specific surface area with increasing temperature ( $\gamma$-alumina was converted to $\alpha$-alumina), 2) decreasing reaction rate due to gas diffusion control, and 3) reaction of $\mathrm{CO}$ with $\mathrm{Cl}_{2}$ (or other chlorinating reagents) prior to the desired heterogeneous chlorination reaction. The chlorination rate of $\alpha$ alumina was 50 to 300 times slower than the chlorination rate of $\gamma$-alumina. The activation energy for four alumina-chlorine reactions is shown in Table 2. Additional investigation of bauxite and $\gamma-\mathrm{Al}_{2} \mathrm{O}_{3}$ chlorination as a means of removing aluminum from parent materials was recommended.

Table 2

Activation Energy for Four Aluminum Oxide-Chlorine Reactions

\begin{tabular}{||c|c|}
\hline \multicolumn{1}{|c|}{ Reaction } & $\mathrm{E}_{\text {act }}$ \\
\hline$\gamma-\mathrm{Al}_{2} \mathrm{O}_{3}+1.5 \mathrm{C}+3 \mathrm{Cl}_{2} \rightarrow 2 \mathrm{AlCl}_{3}+1.5 \mathrm{CO}_{2}$ & 39 \\
\hline$\gamma-\mathrm{Al}_{2} \mathrm{O}_{3}+1.5 \mathrm{C}+3 \mathrm{Cl}_{2}+\mathrm{O}_{2} \rightarrow 2 \mathrm{AlCl}_{3}+1.5 \mathrm{CO}_{2}+\mathrm{O}_{2}$ & 58 \\
\hline$\alpha-\mathrm{Al}_{2} \mathrm{O}_{3}+3 \mathrm{CO}+3 \mathrm{Cl}_{2} \rightarrow 2 \mathrm{AlCl}_{3}+3 \mathrm{CO}_{2}$ & 37 \\
\hline$\gamma-\mathrm{Al}_{2} \mathrm{O}_{3}+3 \mathrm{CO}+3 \mathrm{Cl}_{2} \rightarrow 2 \mathrm{AlCl}_{3}+3 \mathrm{CO}_{2}$ & 38 \\
\hline
\end{tabular}




\subsection{Chlorination of Zirconia}

The commercial production of $\mathrm{Zr}$ metal involves chlorination of purified $\mathrm{ZrO}_{2}$ via the Kroll process. ${ }^{7}$ The chlorinator is operated at $1000^{\circ} \mathrm{C}$ with chlorine, but the chlorination rate can be increased dramatically with the addition of a reducing agent such as $\mathrm{C}$ or $\mathrm{CO}^{8}$ The reactions and activation energies for two zirconia-chlorine reactions are shown in Table 3.

Table 3

Activation Energies for Two Zirconia-Chlorine Reactions

\begin{tabular}{||c|c|}
\hline \multicolumn{1}{|c|}{ Reactions } & $\mathrm{E}_{\text {act }}$ \\
\hline $\mathrm{ZrO}_{2}+\mathrm{Cl}_{2} \rightarrow \mathrm{ZrCl}_{4}+\mathrm{O}_{2}$ & $39.7 \mathrm{kcal} / \mathrm{mol}$ \\
\hline $\mathrm{ZrO}_{2}+\mathrm{C}+\mathrm{Cl}_{2} \rightarrow \mathrm{ZrCl}_{4}+\mathrm{CO}_{2}$ & $30.5 \mathrm{kcal} / \mathrm{mol}$ \\
\hline
\end{tabular}

The activation energy reported for the reaction

$$
\mathrm{ZrO}_{2}+2 \mathrm{CO}+\mathrm{Cl}_{2} \rightarrow \mathrm{ZrCl}_{4}+2 \mathrm{CO}_{2}
$$

ranged from 22.3 to $29.1 \mathrm{kcal}$ over the temperature range studied. The variation in activation energy was attributed to the equilibrium reaction

$$
2 \mathrm{CO} \leftrightarrow \mathrm{CO}_{2}+\mathrm{C} .
$$

\subsection{Chlorination of Uranium}

Chlorination of nuclear fuel was studied in an effort to recover uranium from spent nuclear fuel. The first processing step envisioned for the chlorination scheme was chlorination of the metal material surrounding the fuel (cladding) with gaseous $\mathrm{HCl}$ at 520 to $670 \mathrm{~K} .{ }^{9}$ This chlorination step was used to convert zircaloy cladding to volatile chlorides. A more rigorous secondary chlorination was completed at 970 to $1120 \mathrm{~K}$ with a C-CCl $\mathrm{Cl}_{4}$ gaseous mixture once the cladding was removed in the initial chlorination step,. The major 
components of the fuel material, $\mathrm{U}$ and $\mathrm{Th}$, were chlorinated and volatilized as $\mathrm{UCl}_{3}$ and $\mathrm{ThCl}_{4}$. Chlorination of spent fuel was successful in removing $90 \%$ of the uranium.

\subsection{Chlorination of Plutonium}

Chlorination of $\mathrm{PuO}_{2}$ is used to produce $\mathrm{Pu}$ metal. ${ }^{10}$ Chlorination studies have been performed with several chlorinating reagents including, $\mathrm{Cl}_{2}, \mathrm{HCl}, \mathrm{CCl}_{4}, \mathrm{Cl}_{2}-\mathrm{CCl}_{4}$, and $\mathrm{HCl}$ $\mathrm{CCl}_{4}$. Both $\mathrm{Cl}_{2}$ and $\mathrm{HCl}$ proved to be inadequate reagents as no chlorination was observed using either gas at temperatures ranging from 545 to $790^{\circ} \mathrm{C}$. Pure $\mathrm{CCl}_{4}$ and mixtures of $\mathrm{CCl}_{4}$ with $\mathrm{Cl}_{2}$ and $\mathrm{Ar}$ proved to be adequate chlorinating reagents at temperatures greater than $500^{\circ} \mathrm{C}$. $\mathrm{A} \mathrm{CCl}_{4}-\mathrm{Cl}_{2}$ mixture was preferred as other $\mathrm{CCl}_{4}$ mixtures produced a carbon deposit on the $\mathrm{PuCl}_{3}$ product. Conversion of $\mathrm{PuO}_{2}$ to $\mathrm{PuCl}_{3}$ ranged from 94.2 to $95.4 \%$ using the $\mathrm{CCl}_{4}-\mathrm{Cl}_{2}$ mixture. Chlorinated $\mathrm{Pu}$ was nonvolatile and remained in the solid phase.

\section{$2.5 \mathrm{CCl}_{4}$ Decomposition}

Several $\mathrm{CCl}_{4}$ decomposition studies were identified in the literature. ${ }^{11-13}$ Decomposition was observed at all temperatures greater than $300^{\circ} \mathrm{C}$ and increased dramatically in the presence of a metal oxide catalyst such as $\mathrm{Al}_{2} \mathrm{O}_{3}$. The $\mathrm{CCl}_{4}$ decomposition products included $\mathrm{C}_{2} \mathrm{Cl}_{4}$, $\mathrm{C}_{2} \mathrm{Cl}_{6}, \mathrm{C}_{6} \mathrm{Cl}_{6}, \mathrm{C}$, and $\mathrm{Cl}_{2}$. Each of the pyrolysis reaction products identified in the literature could participate in chlorination reactions.

\section{THEORY}

Two theoretical considerations are important in the development of a chloride volatility process: 1) are the desired chlorination reactions and separations thermodynamically favorable at feasible temperatures, and 2) do the chemical and volatilization reactions occur 
rapidly enough at feasible temperatures. Both of these theoretical considerations are discussed below.

\subsection{Thermodynamic Equilibrium}

The volatilization temperature of selected chlorinated calcine components are shown in Table 4 to illustrate the potential for separating the radioactive and non-radioactive chlorinated calcine components. $\mathrm{AlCl}_{3}, \mathrm{BCl}_{3}$, and $\mathrm{ZrCl}_{4}$ have low volatilization temperatures as compared to other chlorinated calcine components. Ideally, volatile chlorinated calcine components would volatilize at temperatures above $350^{\circ} \mathrm{C}$ and provide a gross separation between non-radioactive and radioactive calcine components.

Rigorous thermodynamic equilibrium calculations were completed to obtain a more accurate estimate of the separation possible via calcine chlorination. The computer code selected to make equilibrium calculations was the Facility for the Analysis of Chemical Thermodynamics $\left(\mathrm{F}^{*} \mathrm{~A}^{*} \mathrm{C}^{*} \mathrm{~T}^{*}\right) . \mathrm{F}^{*} \mathrm{~A}^{*} \mathrm{C}^{*} \mathrm{~T}^{*}$ consists of an extensive database and a library of algorithms designed to complete a variety of thermodynamic computations. The database consists of the thermodynamic properties of over 3800 compounds and a number of binary solutions. ${ }^{14}$ The specific code utilized for this work was EQUILIB. The user specifies the set of reactants and state variables ( $\mathrm{T}$ and $\mathrm{P}$ ) and the products are calculated by EQUILIB. The equilibrium composition is the one with the lowest Gibbs energy at a specified temperature. 
Table 4

Boiling Points of Chlorinated Calcine Components

\begin{tabular}{|c|c|}
\hline Component & $\begin{array}{c}\text { Pure Component Boiling (B) or } \\
\text { Sublimation (S) Point, }{ }^{\circ} \mathrm{C}\end{array}$ \\
\hline $\mathrm{AlCl}_{3}$ & $180.85-\mathrm{S}$ \\
\hline $\mathrm{NaCl}$ & $1413-\mathrm{B}$ \\
\hline $\mathrm{BCl}_{3}$ & $12.5-\mathrm{S}$ \\
\hline Nitrate Salts & $600-$ decompose as $\mathrm{NO}_{\mathrm{x}}$ \\
\hline $\mathrm{CaCl}_{2}$ & $>1600-\mathrm{B}$ \\
\hline $\mathrm{HgCl}$ & $400-\mathrm{B}$ \\
\hline $\mathrm{KCl}$ & $1500-\mathrm{B}$ \\
\hline $\mathrm{MnCl}_{2}$ & $1190-\mathrm{B}$ \\
\hline $\mathrm{ZrCl}_{4}$ & $330-\mathrm{S}$ \\
\hline $\mathrm{CsCl}$ & $1303-\mathrm{B}$ \\
\hline $\mathrm{SrCl}_{2}$ & $2000-\mathrm{B}$ \\
\hline $\mathrm{UCl}_{3}$ & $1727-\mathrm{B}$ \\
\hline $\mathrm{PuCl}_{3}$ & $787-\mathrm{B}$ \\
\hline $\mathrm{NpCl}_{3}$ & $1527-\mathrm{B}$ \\
\hline $\mathrm{AmCl}_{3}$ & $1750-\mathrm{B}$ \\
\hline
\end{tabular}

\subsection{Chemical Kinetics}

There are two ideal models used to describe the chemical reaction between a solid particle and a gas: a constant particle volume model and a shrinking core model as shown in Figure 2. ${ }^{15}$ Two general assumptions are made for the constant particle volume model: 1) reactant gas concentration is constant throughout the particle, and 2) reaction occurs throughout the entire particle at varying rates. Hence, the solid particle reacts continuously and progressively until chemical reaction is complete. The shrinking core model is described as follows. Reaction occurs at the particle surface where an ash layer forms as the reaction 
progresses. Reactant gases and reaction products must diffuse through the ash layer for the reaction to occur at the unreacted core surface. The particle diameter remains constant throughout the entire reaction. Reaction is complete when the solid particle has been converted to ash.

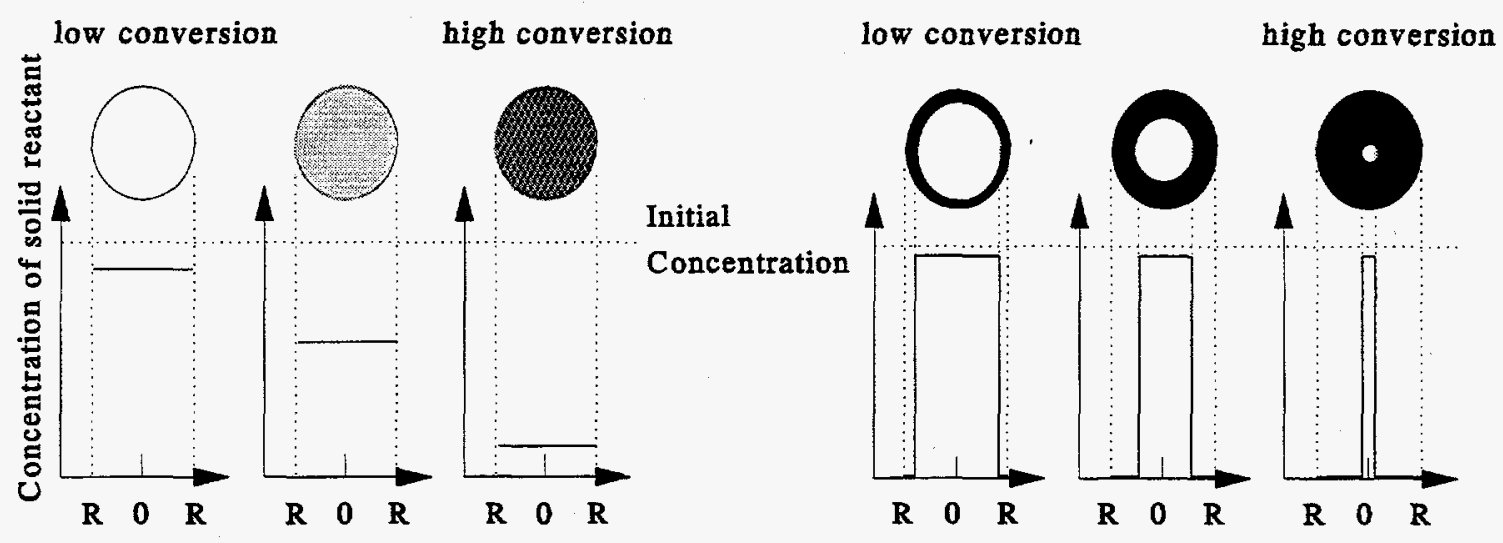

(a)

(b)

Figure 2. Schematic diagram of the (a) constant particle volume and the (b) shrinking core heterogeneous chemical kinetic models.

The actual reaction mechanism is somewhere in between the two ideal cases in most real systems; as reaction occurs at the surface beneath the ash layer, and reactant gases penetrate the particle pores and react in the particle interior. However, the chemical kinetics may be adequately described by one of the ideal models in many cases. 
A summary of the possible mechanistic steps which influence calcine chlorination is shown in Figure 3. Formulation of a global kinetic rate expression is practical when simplifying assumptions can be made to reduce the number of mechanistic steps (see Figure 3) to between one and three. Formulation of an overall kinetic rate expression is not practical where more than three mechanistic steps influence the overall kinetic rate. Instead, a simple first- or second-order rate expression is used to model reaction kinetics where more than three mechanistic steps influence the chemical reaction rate.

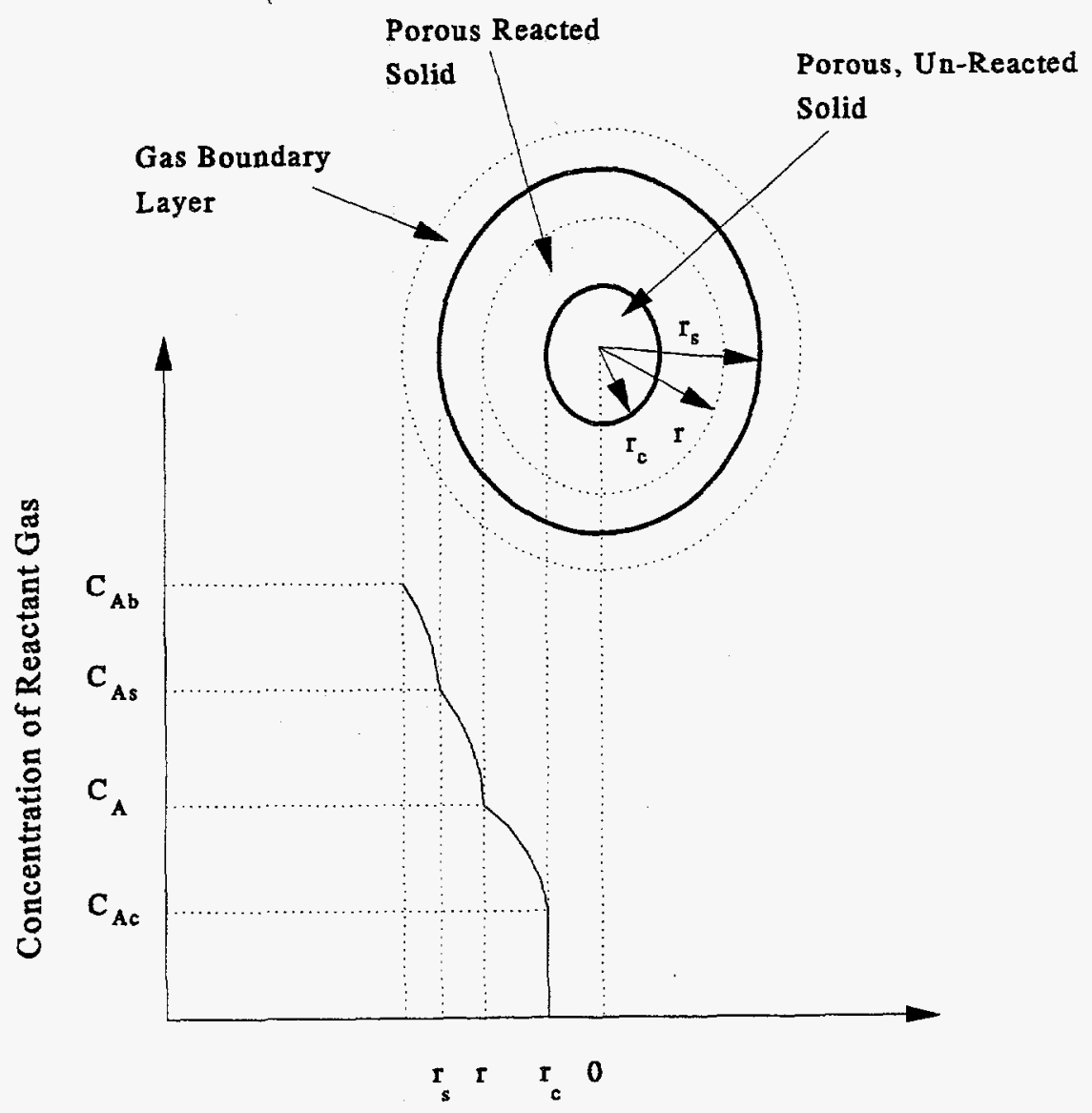

Figure 3. Schematic diagram of a solid particle undergoing chemical reaction with a gas.

The proposed calcine chlorination mechnanistic steps are: 1) diffusion of reactant gas through the stagnant gaseous boundary layer surrounding the particle, 2) pore diffusion, 3) reactant gas diffusion through the ash layer, 4) adsorption of reactant gas at the particle surface, 5) 
global reaction rate expression is impractical. Simplifying assumptions can be made to reduce the ten possible mechanistic steps to one to three, and formulation of a global kinetic expression is practical in many heterogeneous systems. Where more than three mechanistic steps influence the overall kinetic rate, the global kinetic rate expression may be approximated by an empirical first- or second-order rate expression (see Reference 15).

The overall rate expression developed for calcine chlorination was first-order. A dimensionless form of the first-order reaction expression developed is:

$$
\frac{d X_{C a}}{d t}=k x_{A}
$$

where $\mathrm{X}_{\mathrm{Ca}}$ is defined as

$$
X_{C a}=\frac{M_{C a}^{0}-M_{C a}}{M_{C a}^{o}-M_{C a, \min }^{f}},
$$

and $\mathrm{C}_{\mathrm{A}}$ is defined as the total concentration, $\mathrm{C}_{\mathrm{tot}}$ times the reactant gas mole fraction, $\mathrm{x}_{\mathrm{A}}$. The quantity $\mathrm{M}_{\mathrm{Ca} \text { min }}^{\mathrm{f}}$ refers to the mass of calcine remaining at maximum conversion. The concentration of the reactant gas and the volatile reaction products was calculated from the ideal gas law.

\section{EXPERIMENTAL}

The purpose of calcine chlorination experiments was to gather chlorination rate data and to determine the chemical composition of the chlorination reaction products. The calcine mass remaining in the reactor after each chlorination experiment was assumed to correlate to the conversion of calcine. Chemical analyses completed on the reaction products provided chemical composition data. 


\section{EXPERIMENTAL}

The purpose of calcine chlorination experiments was to gather chlorination rate data and to determine the chemical composition of the chlorination reaction products. The calcine mass remaining in the reactor after each chlorination experiment was assumed to correlate to the conversion of calcine. Chemical analyses completed on the reaction products provided chemical composition data.

Three reactor configurations were utilized in an effort to elucidate the reaction kinetics and mechanisms. The reactor configurations tested were a fixed-bed (reactive gases did not directly pass through the bed), a packed/fluidized bed, and a packed-bed reactor (reactive gases passed directly through the bed). The fixed-bed reactor was used to continuously measure calcine mass during the experiment. Kinetic data collected in the fixed-bed reactor was compared to the data collected in the other two reactor configurations. The kinetic data collected in the packed/fluidized-bed and packed-bed reactors were used to determine the effect of gas velocity past the calcine particles on reaction rate. Theoretically, the reaction rate increases with increasing gas velocity as the stagnant boundary layer surrounding the particle is broken down. At sufficiently high gas velocities, the reaction rate is independent of the gas velocity and the effect of bulk gas diffusion on the overall reaction rate is eliminated.

Most experiments were completed with non-radioactive calcine due to its relative abundance, lower cost, lower hazardous and radioactive waste generation rate, and ease of handling in comparison with radioactive calcine. Non-radioactive calcine is similar to radioactive calcine stored on-site and provides a good estimation of radioactive calcine chlorination behavior. Non-radioactive calcine properties such as porosity and surface area were measured with a mercury porosymmeter to enable calculation of a reaction rate per unit surface area. 


\subsection{Experimental Equipment}

Calcine chlorination tests were conducted in a number of configurations including a fixed bed, packed/fluidized bed, and packed bed reactor. The first reactor configuration tested was a fixed-bed reactor as shown in Figure 4. Calcine was placed in a 1" OD quartz basket suspended from a balance by a thin nickel wire. Reactive gases entered the reactor beneath the basket and flowed up past the basket. Hence, the reactive gases did not flow directly through the calcine bed. The off-gas was passed through a condenser where the reaction products were collected. Residual calcine mass was recorded every 30 seconds by an IBM PC (using BalanceTalk software) connected to a Mettler PE-600 balance.

The second reactor configuration tested was a packed/fluidized-bed reactor as shown in Figure 5. Calcine was placed on quartz wool packed into the bottom of a 1"ID quartz reactor tube. Reactive gases were introduced through holes in the bottom portion of the reactor wall. This configuration was a packed bed at low gas flow rates, and a fluidized bed at high gas flow rates. Reactor off-gas was collected in the condenser. The mass of calcine was measured in the reactor before and after each experiment using a Denver Instruments 300D balance.

The third reactor configuration tested was a packed-bed reactor as shown in Figure 6. This reactor configuration was similar to the packed/fluidized-bed setup shown in Figure 5. The major difference between the two configurations is that the gas flow direction was reversed. The packed-bed reactor arrangement was used for radioactive calcine tests due to its small size compared to the other two configurations. Off-gas from the packed-bed reactor was routed through a condenser and a scrubber packed with small pieces of glass tubing and $3 \underline{\mathrm{M}}$ $\mathrm{NaOH}$. The off-gas treatment scheme facilitated the recovery of volatile radioactive species and destroyed any phosgene present. 


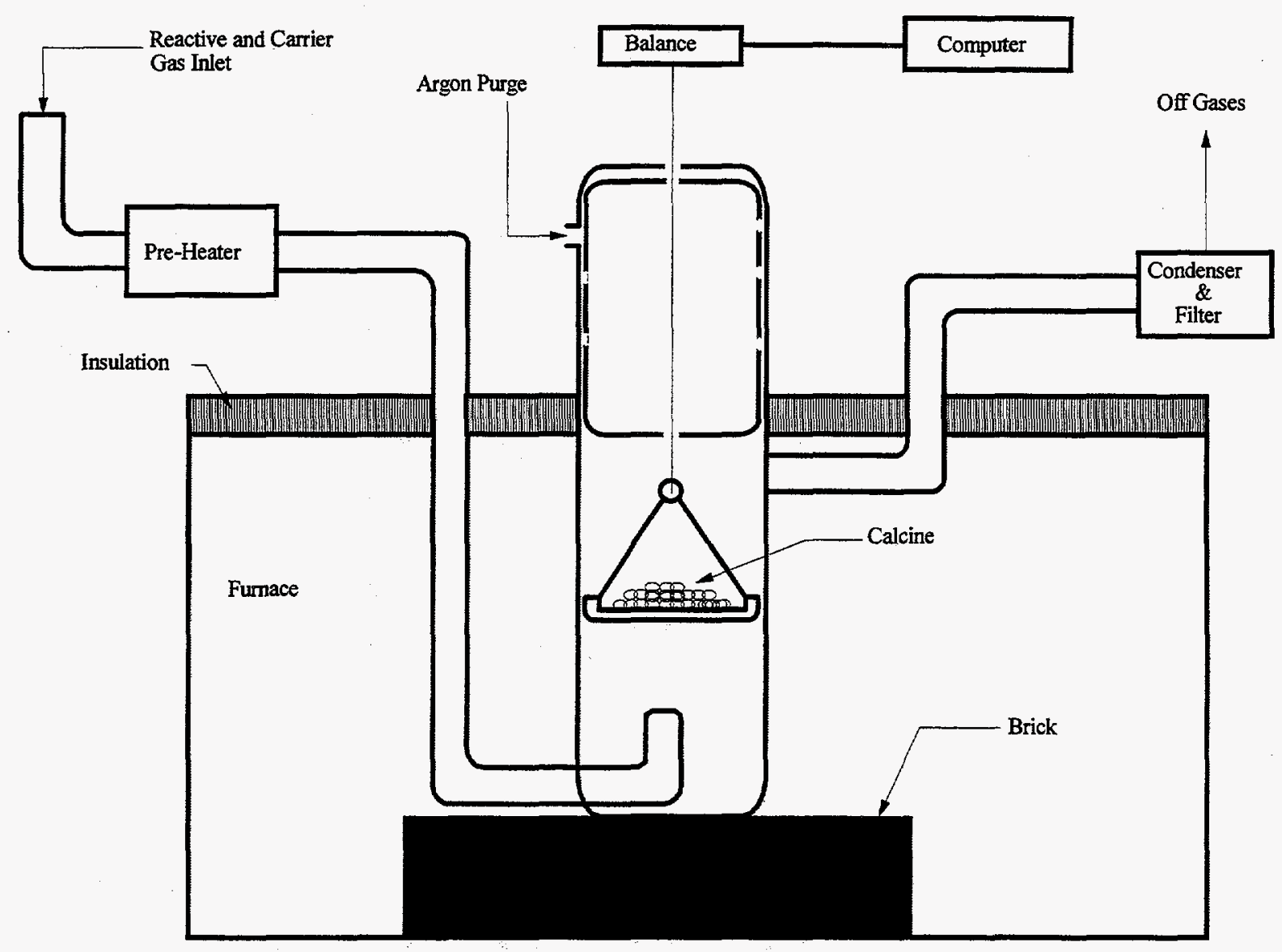

Figure 4. Diagram of the fixed-bed reactor configuration used to study the feasibility of calcine chlorination. 


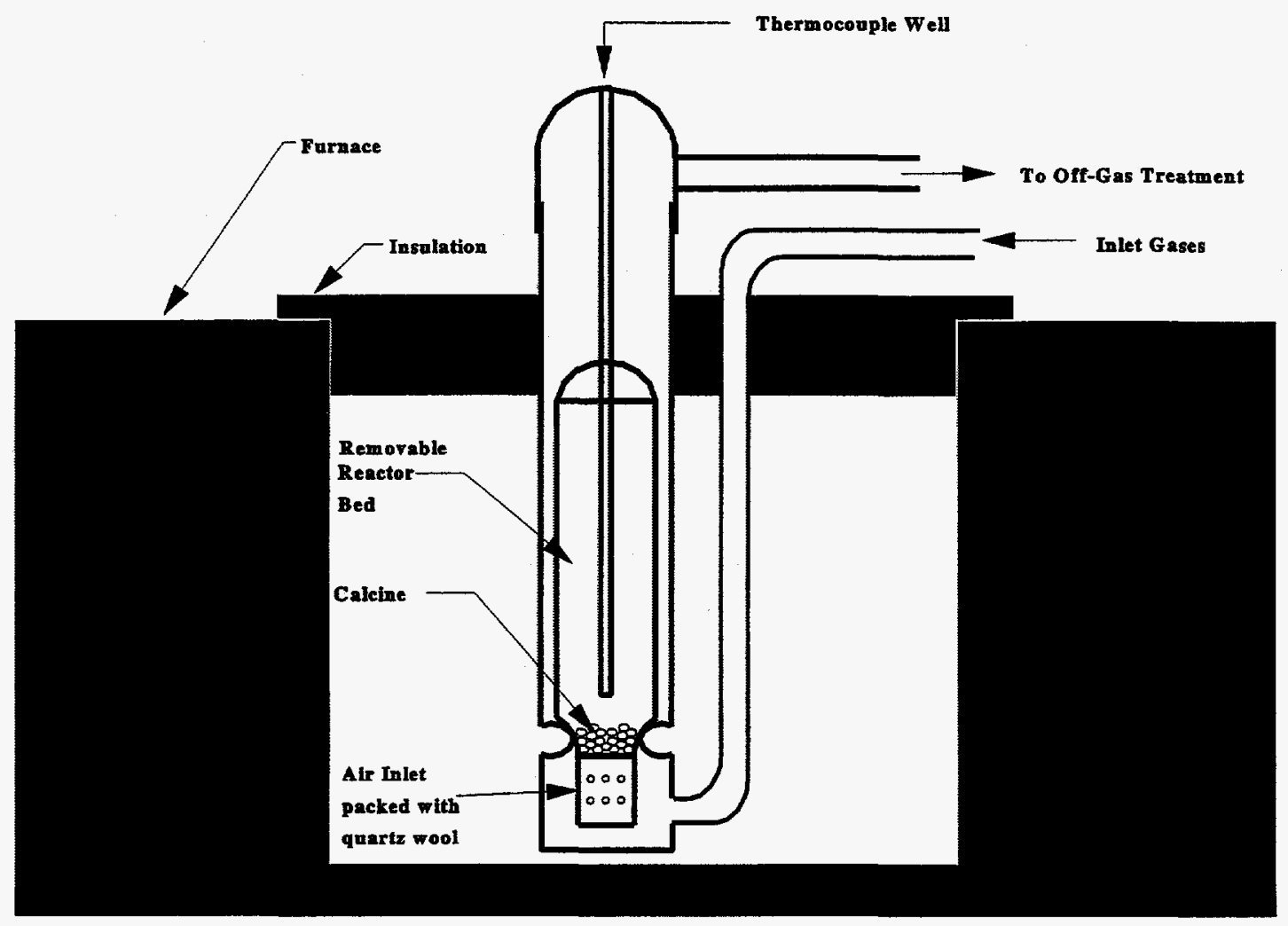

Figure 5. Diagram of the packed/fluidized-bed reactor configuration used to test the feasibility of calcine chlorination. 


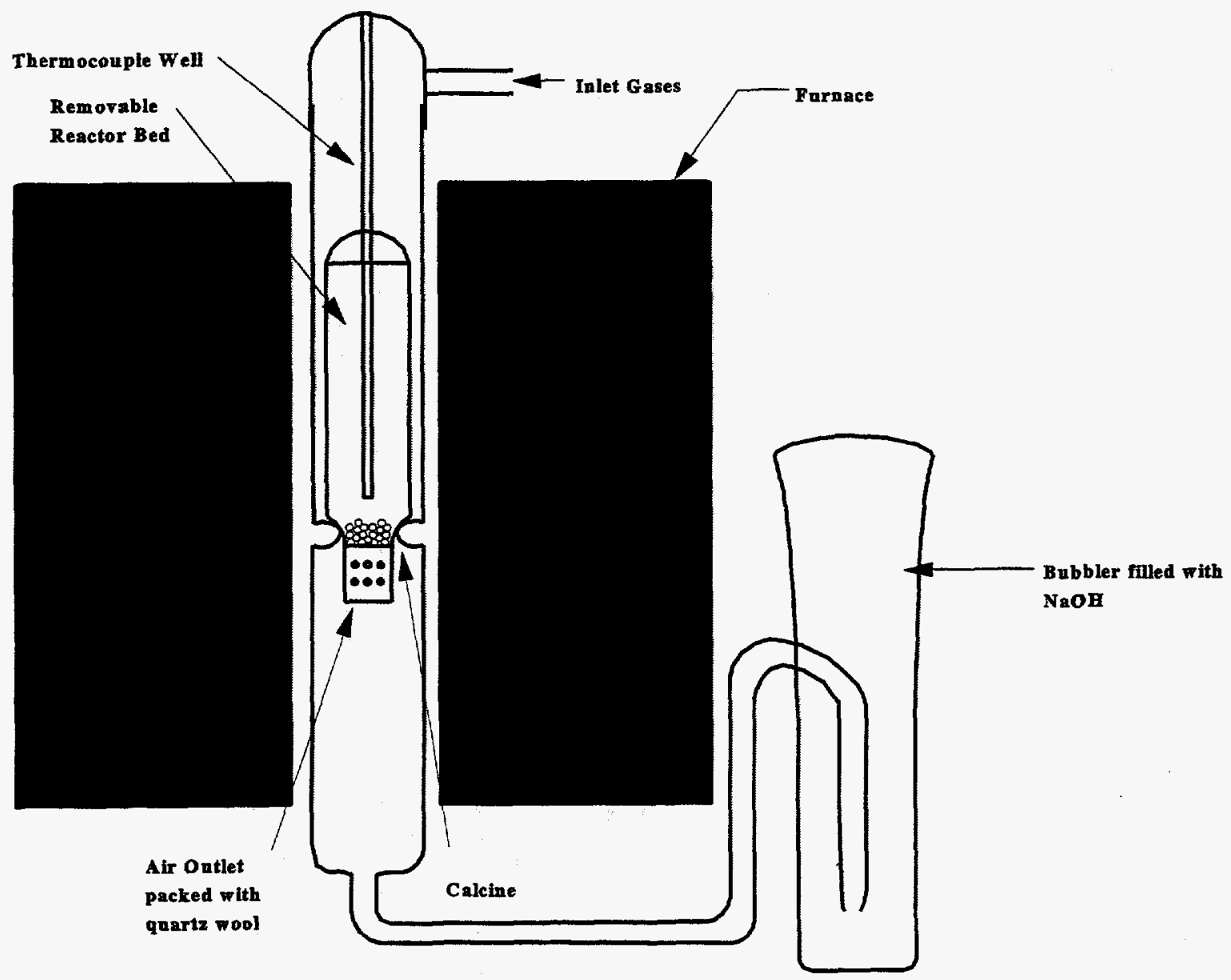

Figure 6. Diagram of the packed-bed reactor configuration used to test the feasibility of calcine chlorination. 
Both $\mathrm{CCl}_{4}$ and $\mathrm{CO}-\mathrm{Cl}_{2}$ were studied as chlorinating gases. Argon was used as the carrier gas in all experiments. The $\mathrm{CCl}_{4}$ feed rate was monitored using a Mettler PE 600 balance linked to an IBM PC in experiments conducted with $\mathrm{CCl}_{4}$ as the chlorinating gas. A schematic of the feed system is shown in Figure 7. The $\mathrm{CCl}_{4}$ flow rate was controlled using a gravity-fed calibrated needle valve. A bubbler did not deliver a consistent and reproducible quantity of $\mathrm{CCl}_{4}$ to the reactor. Argon and $\mathrm{CCl}_{4}$ were mixed in a small chamber heated to $120^{\circ} \mathrm{C}$ to ensure complete vaporization of the $\mathrm{CCl}_{4}$ (boiling point of $\mathrm{CCl}_{4}=76.8^{\circ} \mathrm{C}$ ). A small view port was placed in the lowest area of the $\mathrm{CCl}_{4}$ vaporization chamber to ensure that all $\mathrm{CCl}_{4}$ fed to the reactor was volatilized. During experiments conducted with $\mathrm{CO}-\mathrm{Cl}_{2}$, the reactive gas flow was metered with Johnson-Matthey flowmeters. The argon flow rate was metered with a Sierra Model 900 flow controller. The reactive gas- $\left(\mathrm{CCl}_{4}\right.$ or the $\mathrm{CO}-\mathrm{Cl}_{2}$ mixture $)$ argon mixture were passed through a 3-way valve and introduced into the reactor bed.

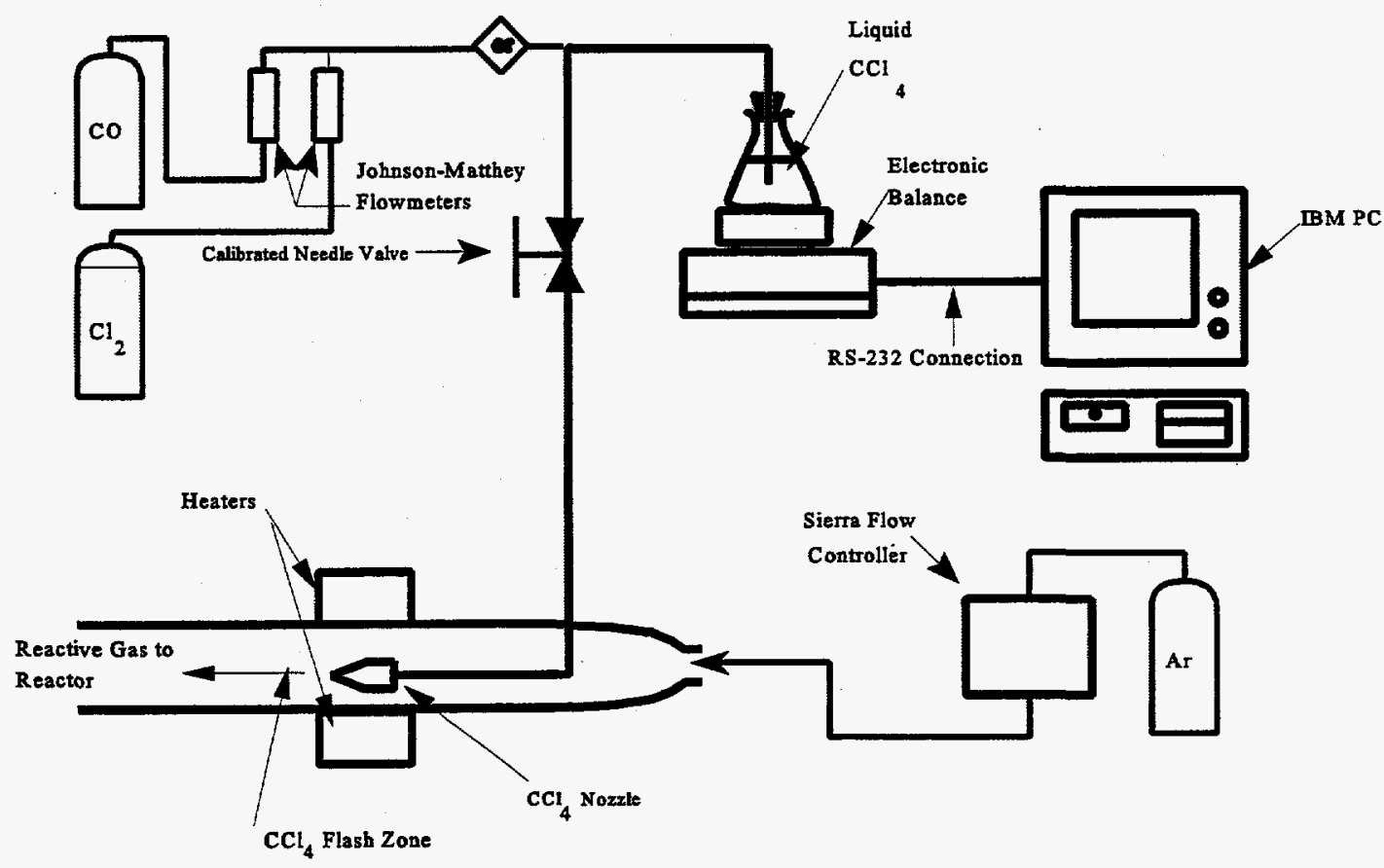

Figure 7. Reactive gas delivery system used in calcine chlorination experiments. 


\subsection{Experimental Materials and Procedure}

The experimental procedure utilized in the three reactor configurations was similar. Each experiment was completed with one gram of calcine, the furnace was heated to the desired temperature, and the reactive gases were introduced to the reactor. Argon was used as the carrier gas in all experiments. The calcine used in all non-radioactive experiments was produced in either Run 77 (alumina) or Run 80 (zirconia) of the 30-cm calciner pilot-plant. The composition of Run 77 and Run 80 calcine is shown in Table 5. As-formed calcine product (mean diameter of $300 \mu \mathrm{m}$ ) was used in all experiments.

Table 5

Chemical Composition of Run 77 and Run 80 Pilot-Plant Calcine (wt\%)

\begin{tabular}{|c|c|c|}
\hline Component & Run 77 Calcine & Run 80 Calcine \\
\hline $\mathrm{Al}_{2} \mathrm{O}_{3}$ & 91.4 & 14.4 \\
\hline $\mathrm{B}_{2} \mathrm{O}_{3}$ & 0.6 & 0.3 \\
\hline $\mathrm{CaO}$ & 0.6 & 25.9 \\
\hline $\mathrm{Ce}_{2} \mathrm{O}_{3}$ & 0.1 & 0.1 \\
\hline $\mathrm{Cr}_{2} \mathrm{O}_{3}$ & 0.2 & 0.7 \\
\hline $\mathrm{Cs}_{2} \mathrm{O}$ & 0.5 & 0.3 \\
\hline $\mathrm{CaF}_{2}$ & 1.7 & 34.1 \\
\hline $\mathrm{Fe}_{2} \mathrm{O}_{3}$ & 0.6 & 0.2 \\
\hline $\mathrm{K}_{2} \mathrm{O}$ & 0.2 & $<0.1$ \\
\hline $\mathrm{Na}_{2} \mathrm{O}$ & 2.5 & 0.3 \\
\hline $\mathrm{NiO}^{\mathrm{O} O}$ & 0.1 & 0.1 \\
\hline $\mathrm{SrO}$ & 0.7 & 0.8 \\
\hline $\mathrm{ZrO}$ & 0.8 & 22.8 \\
\hline
\end{tabular}




\subsubsection{Experimental Procedure}

The experimental procedure for chlorination tests was as follows:

1- Heat calcine to $600^{\circ} \mathrm{C}$ and hold for 30 hours to decompose nitrate salts, flash residual moisture, and to volatilize incomplete combustion products such as $\mathrm{CO}_{\mathrm{x}}$. Heat treatment of the calcine at $600^{\circ} \mathrm{C}$ prior to the experiment is necessary to ensure that the mass loss measured during the experiment is due to chlorination and to volatilization of calcine components.

2- Place 1.0 gram of heat-treated alumina or zirconia calcine in the reactor.

3- Set the furnace to the test temperature.

4- Initiate flow of argon to the chlorination setup using the argon bypass.

5- Initiate chlorinating gas flow $\left(\mathrm{CCl}_{4}\right.$ or the $\mathrm{CO} / \mathrm{Cl}_{2}$ mixture $)$ and start the run timer, once the temperature of the furnace and the reactor vessel have reached the desired set points. (The mass of residual calcine was monitored every two minutes in experiments completed with the thermobalance.)

6- Turn off the reactive gas flow, remove the reactor, and weigh the mass of alumina or zirconia calcine remaining once the desired run time is reached. Record time of reaction, mass of alumina calcine remaining, and reactive gas flows on the run data sheet.

7- Collect samples for chemical analysis as desired. Solid samples were scraped from the condenser and submitted with residual calcine samples for SEM, EDS, $\mathrm{x}$-ray fluorescence, and mercury porosymmetry analysis. Liquid 
samples intended for ICP-MS analysis were prepared by dissolving the condensate in $5 \mathrm{M} \mathrm{HNO}_{3}$ and then diluted to $250 \mathrm{ml}$. Residual alumina calcine samples were dissolved in phosphoric acid at $150^{\circ} \mathrm{C}$ to allow complete dissolution of the calcine.

\subsubsection{Chlorination of $\mathrm{CaCl}_{2}$-Washed Zirconia Calcine}

Two chlorination experiments were completed with samples of $\mathrm{CaCl}_{2}$-washed zirconia calcine to verify an alternative pyrochemical treatment flowsheet in conjunction with Lawrence Livermore National Laboratory (LLNL). $\mathrm{CaCl}_{2}$-washed samples were prepared at LLNL. The purpose for these experiments was to remove fluoride from the calcine prior to chlorination. Theoretically, if the fluoride is removed from zirconia calcine, a separation of radioactive and non-radioactive calcine components could be achieved via chlorination. $\mathrm{CaCl}_{2}$-washed samples were prepared by heating a $50 / 50$ mixture of $\mathrm{CaCl}_{2}$-zirconia calcine to $1000^{\circ} \mathrm{C}$ for several hours. The molten $\mathrm{CaCl}_{2}$-zirconia solution was poured through a silica filter to remove the solids (mainly $\mathrm{ZrO}_{2}$, actinide oxides, and other metal oxides) from the molten salt (mainly $\mathrm{CaF}_{2}$, and $\mathrm{CaCl}_{2}$ ). The solids were sent to the ICPP for chlorination experiments. An approximate chemical composition (determined by x-ray diffraction) of the $\mathrm{CaCl}_{2}$-washed samples is shown in Table 6 .

Chlorination was completed at the ICPP with $3.0 \mathrm{~g}$ samples using $\mathrm{CCl}_{4}$ and a temperature of $900^{\circ} \mathrm{C}$ for 30 minutes. The remainder of the experimental procedure utilized for sample chlorination was as described in Section 4.2.1. 
Table 6

X-Ray Diffraction Analysis of $\mathrm{CaCl}_{2}$-Washed

Zirconia Calcine

\begin{tabular}{|c|c|}
\hline Element & wt\% \\
\hline $\mathrm{F}$ & $<0.4$ \\
\hline $\mathrm{Cl}$ & 39.54 \\
\hline $\mathrm{Mg}$ & 0.57 \\
\hline $\mathrm{Al}$ & 4.23 \\
\hline $\mathrm{Ca}$ & 35.94 \\
\hline $\mathrm{Zr}$ & 18.88 \\
\hline $\mathrm{Hf}$ & .16 \\
\hline $\mathrm{Ta}$ & .23 \\
\hline
\end{tabular}

\subsubsection{Analytical Equipment}

The equipment used to analyze as-formed calcine, chlorinated calcine reaction products, and residual chlorination solids was available at various locations at the Idaho National Engineering Laboratory. SEM and EDS analyses were completed at the Idaho Research Center (IRC) on an integrated Amray Model 1830 and a Kevex model Delta 5 instrument respectively. The combination of the SEM and EDS instruments provided the elemental composition of the solid phase for all elements with an atomic weight greater than 11 (boron). The mercury porosymmeter, model number Poresizer 9320 located at the IRC, was used to measure the calcine porosity and pore diameter and to estimate the calcine surface area. X-ray diffraction analyses were completed at the ICPP on a Kevex Model D5000. ICPMS analysis was completed at the ICPP also. 


\subsection{Experimental Methodology}

Chlorination experiments were completed in the fixed-bed reactor first to allow continuous measurement of the calcine mass in the reactor and to get a feel for the behavior of calcine during chlorination. The kinetic data collected during the experiments were compared to the data found in the literature. Calcine chlorination products were submitted for chemical analyses to obtain separation data. The main drawback of the fixed-bed reactor configuration was poor gas/solid contact.

The packed/fluidized-bed reactor and the packed-bed reactor were used to determine the calcine chlorination rate with improved gas/solid contact. Calcine was removed from the reactor and weighed manually after each experiment to compile kinetic data. Thus, a new sample was required for each experiment. Initially, a series of 20 statistically designed experiments were completed in the packed/fluidized-bed reactor with an equimolar mixture of $\mathrm{CO}-\mathrm{Cl}_{2}$ diluted in $85 \mathrm{~mol} \%$ argon. The purpose of the statistically-designed experiments was to determine which experimental parameter(s) (i.e., time, temperature, and gas flow rate) affected the reaction kinetics the most. The experimental design and results analyses were completed using XSTAT software. Based on the results of the statistically-designed experiments, chlorination experiments were completed with $\mathrm{CCl}_{4}$ in place of $\mathrm{CO}-\mathrm{Cl}_{2}$ to determine the effect of reactive gas on the reaction rate. The use of $\mathrm{CCl}_{4}$ allowed completion of many experiments as the reaction time was decreased substantially.

Based on the results obtained in the statistically-designed experiments, an extensive parametric study was completed in the packed/fluidized-bed and packed bed reactor with $\mathrm{CCl}_{4}$ to determine the effect of reactive gas concentration (or mole fraction), gas flow rate, and temperature on the chlorination rate. The mole fraction of $\mathrm{CCl}_{4}$ was varied from 0.08 to 0.46 , the total gas flow rate was varied from 100 to $1404 \mathrm{ml} / \mathrm{min}\left(25^{\circ} \mathrm{C}, 1 \mathrm{~atm}\right)$, and the temperature was varied from 500 to $800^{\circ} \mathrm{C}$, to complete the parametric study. The 
parametric study data was analyzed to elucidate the reaction kinetics and to compare the performance of the two reactor configurations.

The drawback of the packed/fluidized-bed reactor was poor filtration of the reactor off-gas. Hence, separation data was not collected in the packed/fluidized-bed reactor. The packedbed reactor was used to determine the separation achieved via chlorination. Non-radioactive samples tested in the packed-bed reactor were submitted for ICP-MS analysis. Radioactive samples tested in the packed-bed reactor were submitted to analytical chemistry for radioanalysis.

\section{RESULTS}

The results obtained from the calcine chlorination study are presented below. Results include thermodynamic equilibrium calculations, elemental analysis of reaction products, SEM photographs, EDS elemental phase composition, phases determined by x-ray diffraction, calcine pore size and surface area measured with a mercury porosymmeter, and residual calcine mass and/or calcine conversion.

\section{$5.1 \mathrm{~F}^{*} \mathrm{~A}^{*} \mathrm{C}^{*} \mathrm{~T} *$ Thermodynamic Equilibrium Calculations}

The basic assumptions used to complete equilibrium calculations were: 1) ideal gas behavior; 2) ideal pure solids for condensed phases; and 3) a basis of 100 grams of calcine, 250 grams of $\mathrm{CCl}_{4}$, and 1000 grams of argon. Calculations were completed using the calcine compositions for Run 77 (alumina) and Run 80 (zirconia) pilot plant calcine with $0.002 \mathrm{~g}$ of $\mathrm{U}_{2} \mathrm{O}_{3}$ added to estimate the behavior of actinide elements. Also, excess chlorinating reagent and argon were added to in the calculations to simulate long chlorination times. The results of the equilibrium calculations are summarized in Table 7. 
Table 7

Calculated Chemical Composition of Alumina and Zirconia Calcine Chlorinated at $600^{\circ} \mathrm{C}$

\begin{tabular}{|c|c|c|}
\hline \multirow{2}{*}{ Component } & \multicolumn{2}{|c|}{ Solids (g) } \\
\hline & Run 77 (Alumina) Calcine & Run 80 (Zirconia) Calcine \\
\hline $\mathrm{Al}_{2} \mathrm{O}_{3}$ & 4.40 & 0.00 \\
\hline $\mathrm{AlF}_{3}$ & 0.00 & 23.7 \\
\hline $\mathrm{B}_{2} \mathrm{O}_{3}$ & 0.12 & 0.00 \\
\hline $\mathrm{CaO}$ & 0.22 & 0.00 \\
\hline $\mathrm{CaCl}_{2}$ & 1.75 & 98.32 \\
\hline $\mathrm{CaF}_{2}$ & 0.41 & 1.00 \\
\hline $\mathrm{Fe}_{2} \mathrm{O}_{3}$ & 0.18 & 0.00 \\
\hline $\mathrm{K}_{2} \mathrm{O}$ & 0.02 & 0.00 \\
\hline $\mathrm{Mn}$ & 0.50 & 0.00 \\
\hline $\mathrm{Na}_{2} \mathrm{O}$ & 0.62 & 0.00 \\
\hline $\mathrm{SO}_{4}$ & 1.20 & 0.00 \\
\hline $\mathrm{ZrO}_{2}$ & 0.34 & 0.00 \\
\hline $\mathrm{NaCl}$ & 4.68 & 0.00 \\
\hline $\mathrm{KCl}$ & 0.11 & 0.00 \\
\hline \multicolumn{3}{|c|}{ Gases $(\mathrm{g})$} \\
\hline $\mathrm{AlCl}_{3}$ & 218.23 & 0.02 \\
\hline $\mathrm{BCl}_{3}$ & 1.61 & 0.00 \\
\hline $\mathrm{FeCl}_{3}$ & 0.85 & 0.00 \\
\hline $\mathrm{ZrCl}_{4}$ & 0.64 & 43.12 \\
\hline $\mathrm{CsCl}$ & 0.002 & 0.002 \\
\hline $\mathrm{UCl}_{3}$ & 0.0025 & 0.0025 \\
\hline Total Gas & 221.33 & 43.14 \\
\hline Initial Weight & 100.00 & 100.00 \\
\hline Final Weight (solids) & 14.5 & 123.02 \\
\hline$\%$ Mass Change & -85.5 & 23.02 \\
\hline
\end{tabular}




\subsection{Analytical Results}

Analytical results include SEM photographs, EDS elemental analysis, $\mathrm{x}$-ray diffraction analysis, mercury porosymmetry measurements, ICP-MS analysis of calcine chlorination products, and radioanalysis of radioactive calcine chlorination products.

\subsubsection{Analytical Results for Zirconia Calcine}

Analyses completed on chlorinated zirconia calcine included SEM, EDS, mercury porosymmetry, and x-ray diffraction of residual solid material. No measurable quantities of volatile reaction products were collected. The SEM micrographs of unreacted zirconia calcine and chlorinated zirconia calcine (see Figure 8) revealed that little visible change had taken place during calcine chlorination.

An elemental map of chlorinated zirconia calcine (chlorinated at $600^{\circ} \mathrm{C}$ in the fixed-bed reactor) generated with EDS is shown in Figure 9. This map is a composite image revealing the relative abundance of the elements chlorine, zirconium, calcium, oxygen, aluminum, fluorine, and sulphur. Isocolorometric areas are indicative of a particular element. It appears that high concentrations of chlorine are located near high concentrations of calcium. High concentrations of fluorine appear to be near high concentrations of aluminum and calcium. The elemental analysis completed with EDS is shown in Table 8. 


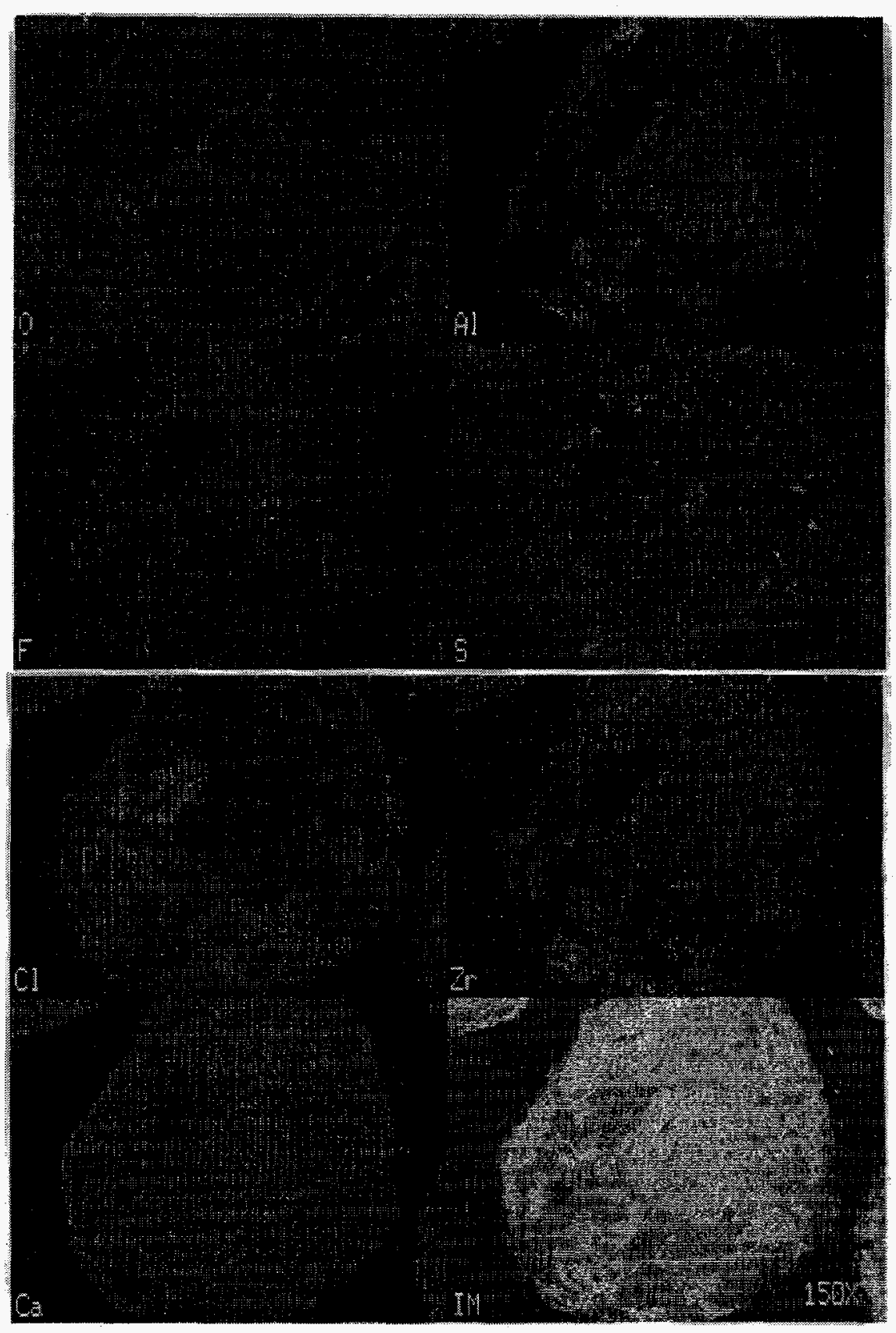

Figure 9. SEM elemental map of chlorinated zirconia pilot-plant calcine. 
Table 8

EDS Analysis of Residual Solids from Chlorinated Zirconia Calcine

\begin{tabular}{|c|c|}
\hline Element & Composition (Mol \%) \\
\hline $\mathrm{O}$ & 39.6 \\
\hline $\mathrm{F}$ & 12.16 \\
\hline $\mathrm{Na}$ & 0.55 \\
\hline $\mathrm{Al}$ & 3.73 \\
\hline $\mathrm{Cl}$ & 25.68 \\
\hline $\mathrm{K}$ & 0.4 \\
\hline $\mathrm{Ca}$ & 13.48 \\
\hline $\mathrm{Sr}$ & 0.46 \\
\hline $\mathrm{Zr}$ & 3.93 \\
\hline
\end{tabular}

Results obtained from x-ray diffraction of zirconia calcine and chlorinated zirconia calcine (chlorinated at $600^{\circ} \mathrm{C}$ in the fixed-bed reactor with $\mathrm{CO}-\mathrm{Cl}_{2}$ ) are shown in Table 9. The compounds identified in the chlorinated zirconia calcine verify the observations of the elemental map. The major components of chlorinated zirconia calcine were $\mathrm{CaClF}, \mathrm{ZrO}_{2}$, and $\mathrm{CaF}_{2}$. Other components identified included $\mathrm{Ca}_{0.15} \mathrm{Zr}_{0.85} \mathrm{O}_{1.85}, \mathrm{CaO}, \mathrm{CaCl}_{2}$, and $\mathrm{AlF}_{3}$.

Table 9

X-Ray Diffraction Analysis Results of Zirconia Calcine

\begin{tabular}{||l|l|l||}
\hline Sample & Principal Constituents & Minor Constituents \\
\hline Before Chlorination & $\mathrm{CaF}_{2}$ & $\mathrm{AlF}_{3}, \mathrm{CaSO}_{4}$, and $\mathrm{ZrO}_{2}$ \\
\hline After Chlorination & $\mathrm{CaClF}, \mathrm{ZrO}_{2}$, and $\mathrm{CaF}_{2}$ & $\begin{array}{l}\mathrm{Ca}_{.15} \mathrm{Zr}_{.85} \mathrm{O}_{1.85}, \mathrm{CaO}, \mathrm{CaCl}_{2}, \\
\mathrm{AlF}_{3}, \text { and } \mathrm{CaCl}_{2} \cdot 6 \mathrm{H}_{2} \mathrm{O}\end{array}$ \\
\hline
\end{tabular}


Mercury porosymmetry results of zirconia and chlorinated zirconia calcine (chlorinated at $600^{\circ} \mathrm{C}$ with $\mathrm{CO}-\mathrm{Cl}_{2}$ ) are shown in Table 10 . The total pore area, total intrusion volume, the pore diameter, and the porosity of zirconia calcine appear to decrease during chlorination.

Table 10

Mercury Porosymmetry Results of Zirconia Calcine

Before and After Chlorination

\begin{tabular}{||l|l|l|l|l|l||}
\hline Sample & $\begin{array}{l}\text { Total } \\
\text { Intrusion } \\
\text { Volume } \\
(\mathrm{ml} / \mathrm{g})\end{array}$ & $\begin{array}{l}\text { Total } \\
\text { Pore Area } \\
\left(\mathrm{m}^{2} / \mathrm{g}\right)\end{array}$ & $\begin{array}{l}\text { Average } \\
\text { Pore } \\
\text { Diameter } \\
(\mu \mathrm{m})\end{array}$ & $\begin{array}{l}\text { Bulk Density } \\
(\mathrm{g} / \mathrm{ml})\end{array}$ & Porosity $(\%)$ \\
\hline $\begin{array}{l}\text { Before } \\
\text { Chlorination }\end{array}$ & 0.1471 & 7.092 & 0.0829 & 2.2035 & 32.40 \\
\hline $\begin{array}{l}\text { After } \\
\text { Chlorination }\end{array}$ & 0.0649 & 3.42 & 0.0759 & 2.6926 & 17.47 \\
\hline
\end{tabular}

\subsubsection{Analytical Results for Zirconia Calcine Washed with $\mathrm{CaCl}_{2}$}

Zirconia calcine was blended with an equal weight of $\mathrm{CaCl}_{2}$, heat treated at $1000^{\circ} \mathrm{C}$, and filtered to remove residual oxides in an effort to remove fluoride from the calcine prior to treatment via chlorination (see Section 4.2.2). The residual oxide material collected during the $\mathrm{CaCl}_{2}$ wash was subjected to chlorination with $\mathrm{CCl}_{4}$ at $900^{\circ} \mathrm{C}$. The solid sample weight decreased from $3.0 \mathrm{~g}$ to $2.3 \mathrm{~g}$ ( $23 \mathrm{wt} \%$ ) during chlorination which indicated volatilization of some sample components. The off-gas condensate was subjected to x-ray diffraction analysis. The components identified in the off-gas were mainly $\mathrm{C}_{6} \mathrm{Cl}_{6}$, a degradation product of $\mathrm{CCl}_{4}$ and a trace of $\mathrm{Zr}$. The volatile components which caused the weight loss observed in the experiment were not identified. 


\subsubsection{Analytical Results for Alumina Calcine}

Analyses of chlorinated alumina calcine included SEM, EDS, $x$-ray diffraction, mercury porosymmetry, and ICP-MS. SEM micrographs of unreacted alumina calcine, alumina calcine chlorinated at $600^{\circ} \mathrm{C}$ in the fixed-bed reactor with $\mathrm{CO}-\mathrm{Cl}_{2}$, and condensed reaction product are shown in Figure 10. The average particle size appears to decrease during reaction. This decreasing particle size is verified by visual inspection of chlorinated alumina calcine as compared to as-formed calcine in all chlorination experiments. This decreasing particle size can be attributed to attrition rather than a shrinking core reaction mechanism as full-size, low density, calcine particles are visible in the SEM photographs. Visual inspection of chlorinated calcine product also corroborates this result as full-size low-density calcine particles are observed to cling to the sample bottle wall after all chlorination experiments. 


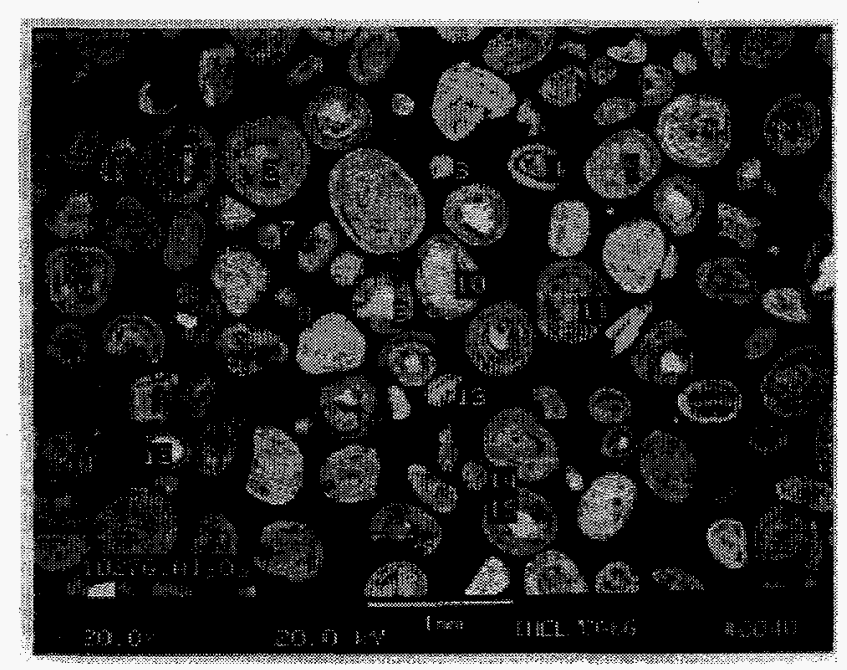

(a)

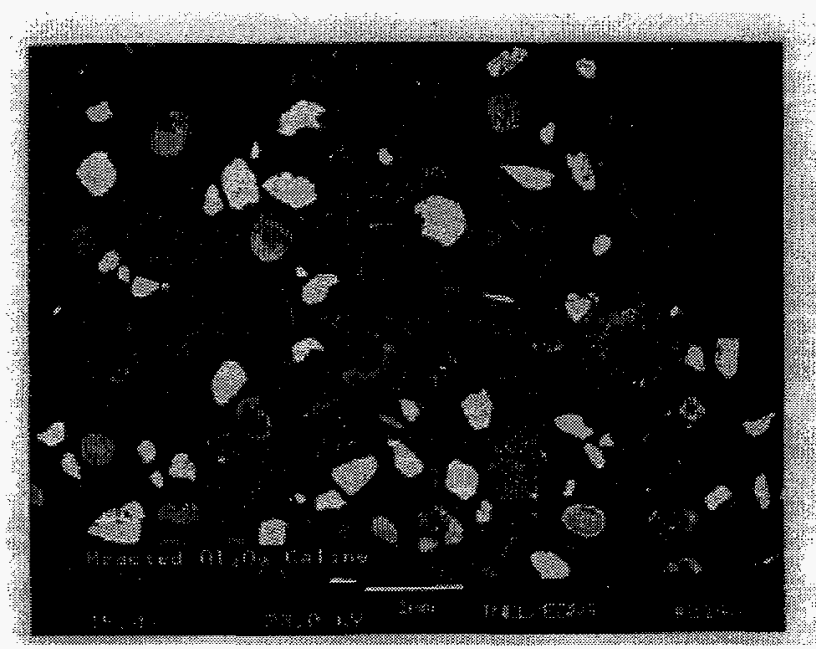

(b)

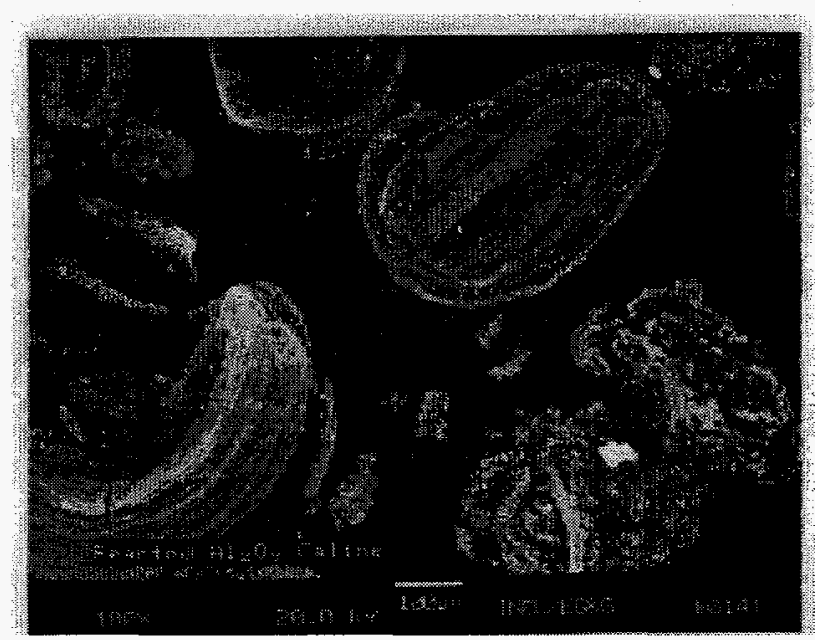

(c)

Figure 10. SEM photographs of chlorinated alumina pilot-plant calcine and condensed volatile species; a) Photograph before chlorination (20x), b) Photograph after chlorination (15x), and c) Photograph after chlorination (100x). 
EDS elemental analysis of alumina calcine chlorinated at $600^{\circ} \mathrm{C}$ in the fixed-bed reactor with $\mathrm{CO}$ $\mathrm{Cl}_{2}$ and condensed reaction product is shown in Table 11. Many of the elements identified in the unreacted calcine are not identified in the condensed reaction product.

Table 11

SEM and EDS Analysis of Residual Calcine from Alumina

Calcine Chlorination Experiments

\begin{tabular}{|c|c|c||}
\hline Element & $\begin{array}{c}\text { Residual Solids } \\
\text { Average Composition } \\
(\mathrm{mol} \%)\end{array}$ & $\begin{array}{c}\text { Condensed Volatile Reaction } \\
\text { Product Composition } \\
\text { (mol\%) }\end{array}$ \\
\hline $\mathrm{O}$ & 55.54 & 60.83 \\
\hline $\mathrm{Mg}$ & 1.3875 & 0.00 \\
\hline $\mathrm{Al}$ & 36.0975 & 11.87 \\
\hline $\mathrm{P}$ & 1.61 & 0.00 \\
\hline $\mathrm{S}$ & 1.5525 & 0.00 \\
\hline $\mathrm{Cl}$ & 2.465 & 27.29 \\
\hline $\mathrm{Ca}$ & 1.3 & 0.00 \\
\hline $\mathrm{Mn}$ & 0.005 & 0.00 \\
\hline $\mathrm{Fe}$ & 0.02 & 0.00 \\
\hline $\mathrm{Cu}$ & 0.035 & 0.00 \\
\hline
\end{tabular}

$\mathrm{X}$-ray diffraction results for alumina calcine chlorinated at $600^{\circ} \mathrm{C}$ in the fixed-bed reactor with CO$\mathrm{Cl}_{2}$ and condensed reaction product are shown in Table 12. Compounds of aluminum are the principal components of each sample. Major components are present in the sample in concentrations greater than $15 \mathrm{wt} \%$. Minor components can be present in concentrations less than $15 \mathrm{wt} \%$. 
Table 12

X-Ray Diffraction Analysis of

Unreacted and Chlorinated Alumina Calcine

\begin{tabular}{|c|c|c|}
\hline Sample & Major Constituents & Minor Constituents \\
\hline Before Chlorination & $\gamma-\mathrm{Al}_{2} \mathrm{O}_{3}$ & $\begin{array}{l}\alpha-\mathrm{Al}_{2} \mathrm{O}_{3} \approx 2 \%, \delta-\mathrm{Al}_{2} \mathrm{O}_{3} \text { and } \\
\text { amorphous } \mathrm{Al}_{2} \mathrm{O}_{3}\end{array}$ \\
\hline After Chlorination & None Identified & $\begin{array}{l}\alpha-\mathrm{Al}_{2} \mathrm{O}_{3} \approx 6 \%, \gamma-\mathrm{Al}_{2} \mathrm{O}_{3}, \beta-\mathrm{Al}_{2} \mathrm{O}_{3}, \\
\mathrm{CaSO}_{4}, \text { and } \mathrm{CaCl}\end{array}$ \\
\hline $\begin{array}{l}\text { Condensed Off-gas } \\
\text { from Chlorination }\end{array}$ & $\mathrm{AlCl}_{3} \cdot 6 \mathrm{H}_{2} \mathrm{O}$ & $\begin{array}{l}\mathrm{CaSO}_{4}, \mathrm{CaF}_{2}, \mathrm{Ca}(\mathrm{ClO})_{2} \cdot 3 \mathrm{H}_{2} \mathrm{O} \text {, and } \\
\mathrm{Ca}\left(\mathrm{PO}_{3}\right)_{2}\end{array}$ \\
\hline
\end{tabular}

The results of mercury porosymmetry measurements on unreacted and reacted alumina calcine (chlorinated at $600^{\circ} \mathrm{C}$ with $\mathrm{CO}-\mathrm{Cl}_{2}$ in the fixed-bed reactor) are shown in Table 13. The total pore diameter, total intrusion volume, and porosity increased, whereas the total pore area decreased during chlorination.

Table 13

Mercury Porosymmetry Results of Alumina Pilot-Plant Calcine

Before and After Chlorination

\begin{tabular}{||l|l|l|l|l|l||}
\hline \hline Sample & $\begin{array}{l}\text { Total } \\
\text { Intrusion } \\
\begin{array}{l}\text { Volume } \\
(\mathrm{m} / \mathrm{g})\end{array}\end{array}$ & $\begin{array}{l}\text { Total } \\
\text { Pore Area } \\
\left(\mathrm{m}^{2} / \mathrm{g}\right)\end{array}$ & $\begin{array}{l}\text { Average } \\
\text { Pore } \\
\text { Diameter } \\
(\mu \mathrm{m})\end{array}$ & $\begin{array}{l}\text { Bulk Density } \\
(\mathrm{g} / \mathrm{ml})\end{array}$ & Porosity (\%) \\
\hline $\begin{array}{l}\text { Before } \\
\text { Chlorination }\end{array}$ & 0.3972 & 63.872 & 0.0249 & 1.1878 & 47.18 \\
\hline $\begin{array}{l}\text { After } \\
\text { Chlorination }\end{array}$ & 0.5275 & 46.383 & 0.0455 & 1.0957 & 57.79 \\
\hline
\end{tabular}

ICP-MS analysis of alumina calcine chlorinated in the packed-bed reactor at $600^{\circ} \mathrm{C}$ with an equimolar $\mathrm{CO}-\mathrm{Cl}_{2}$ mixture for two hours and condensed reaction product is shown in Table 
14. Nearly all calcine components are associated with the volatilized reaction products, and a clean separation between components was not achieved.

Table 14

Elemental Analysis of Off-Gas and Residual Solid Samples Taken During Chlorination of Non-Radioactive Alumina Calcine

\begin{tabular}{|c|c|c|c|c|c||}
\hline \multirow{2}{*}{ Element } & \multicolumn{5}{|c|}{ Run \# } \\
\cline { 2 - 6 } & \multirow{2}{*}{ Before } & \multicolumn{2}{|c|}{1} & \multicolumn{2}{c||}{2} \\
\cline { 2 - 6 } & & Solids $(\mathrm{g})$ & $\begin{array}{c}\text { Condensate } \\
(\mathrm{g})\end{array}$ & Solids $(\mathrm{g})$ & $\begin{array}{c}\text { Condensate } \\
(\mathrm{g})\end{array}$ \\
\hline $\mathrm{Al}$ & 0.465 & 0.0902 & 0.380 & 0.147 & 0.325 \\
\hline $\mathrm{B}$ & 0.002 & 0.000154 & $7.8 \times 10^{-4}$ & $4.76 \times 10^{-4}$ & $4.38 \times 10^{-4}$ \\
\hline $\mathrm{Cs}$ & 0.004 & $<8 \times 10^{-5}$ & $3.25 \times 10^{-5}$ & $<8 \times 10^{-6}$ & $2.3 \times 10^{-5}$ \\
\hline $\mathrm{Na}$ & 0.002 & $7.68 \times 10^{-4}$ & $2.1 \times 10^{-3}$ & $8.16 \times 10^{-4}$ & $2.0 \times 10^{-3}$ \\
\hline $\mathrm{Sr}$ & 0.005 & $5.76 \times 10^{-6}$ & $<2.5 \times 10^{-6}$ & $5.1 \times 10^{-6}$ & $3.25 \times 10^{-6}$ \\
\hline \hline Total & 0.478 & 0.091 & 0.382 & 0.148 & 0.327 \\
\hline
\end{tabular}

\subsubsection{Analytical Results for Radioactive Calcine}

The calcine used for radioactive calcine chlorination tests was retrieved from a sample storage rack at the Remote Analytical Laboratory (RAL). The sample was labelled as 3-way blend calcine ( $a$ blend of liquid sodium waste, aluminum waste, and non-radioactive aluminum nitrate calcined in the New Waste Calciner Facility). The composition of this material was thought to closely correspond to the alumina calcine currently stored in the onsite bin storage area. However, as the test progressed, it was obvious that the material retrieved for this test was not alumina calcine as little off-gas condensate was collected during the chlorination experiment. Chemical analysis of the calcine (available after the tests were completed) revealed that $\mathrm{CaF}_{2}$ was present in the calcine. Hence, separation of radioactive and non-radioactive components was not achieved as limited amounts of chlorine 
reacted with the calcine to produce non-volatile chlorides such as $\mathrm{CaCl}_{2}$ and $\mathrm{AlF}_{3}$ as demonstrated with non-radioactive zirconia calcine chlorination tests. All glassware was rinsed and the rinsate was sent to a counting room to determine the presence of certain radionuclides. Three experiments were completed at $600^{\circ} \mathrm{C}$ with the radioactive calcine: two with $\mathrm{CO}-\mathrm{Cl}_{2}$ diluted in argon and one (a blank) with argon only. Radioanalysis of unreacted calcine and condensed reaction product are shown in Table 15 for Cs.

Table 15

Analytical Results from Radioactive Calcine Chlorination Tests

\begin{tabular}{|c|c|c|c|}
\hline Sample & 1 & 2 & Blank \\
\hline \multicolumn{4}{|c|}{ Unreacted Calcine Analytical Results } \\
\hline${ }^{134} \mathrm{Cs}(\mathrm{g})$ & $2.89 \times 10^{-12}$ & $2.89 \times 10^{-12}$ & $2.89 \times 10^{-12}$ \\
\hline${ }^{137} \mathrm{Cs}(\mathrm{g})$ & $6.97 \times 10^{-6}$ & $6.97 \times 10^{-6}$ & $6.97 \times 10^{-6}$ \\
\hline \multicolumn{4}{|c|}{ Analytical Results from Chlorination Experiments } \\
\hline $\begin{array}{c}{ }^{134} \mathrm{Cs} \text { in Condenser } \\
(\mathrm{g})\end{array}$ & $1.08 \times 10^{-12}$ & $7.82 \times 10^{-13}$ & $6.47 \times 10^{-15}$ \\
\hline $\begin{array}{c}{ }^{137} \mathrm{Cs} \text { in Condenser } \\
(\mathrm{g})\end{array}$ & $3.09 \times 10^{-6}$ & $2.25 \times 10^{-6}$ & $2.38 \times 10^{-8}$ \\
\hline${ }^{134} \mathrm{Cs}$ in Bubbler $(\mathrm{g})$ & 0 & $1.92 \times 10^{-15}$ & 0 \\
\hline${ }^{137} \mathrm{Cs}$ in Bubbler $(\mathrm{g})$ & 0 & $6.73 \times 10^{-9}$ & $9.02 \times 10^{-10}$ \\
\hline $\begin{array}{c}{ }^{134} \text { Cs Collected in } \\
\text { off-gas (Mass } \\
\text { Fraction) }\end{array}$ & 0.374 & 0.271 & 0.002 \\
\hline $\begin{array}{c}{ }^{137} \text { Cs Collected in } \\
\text { off-gas (Mass } \\
\text { Fraction) }\end{array}$ & 0.443 & 0.322 & 0.003 \\
\hline
\end{tabular}

Radioactive Cs was chlorinated and volatilized from the residual calcine solids. Run numbers 1 and 2 were completed under identical conditions for nearly two hours; however the carbon monoxide flow rate for Run 2 dropped $90 \%$ after 100 minutes. The blank run was 
completed under the same conditions as Run 1 and 2 except $\mathrm{Cl}_{2}$ and $\mathrm{CO}$ were not introduced to the reactor.

\subsection{Chemical Kinetics}

Experiments were completed in all reactor configurations (see Figure 4, 5, and 6) to determine the rate of calcine mass change due to pilot-plant calcine chlorination. The majority of the mass loss experiments were completed with simulated alumina calcine since the results of thermodynamic calculations showed that a gross separation of zirconia calcine components via chlorination was not feasible. A few zirconia calcine chlorination experiments were completed to verify the results of the equilibrium calculations.

\subsubsection{Fixed-Bed Mass Change Results for Alumina and Zirconia Calcine}

The results from experiments completed in the fixed-bed reactor were plotted as calcine mass remaining in the reactor as a function of reaction time. The results for an alumina calcine chlorination experiment completed at $600^{\circ} \mathrm{C}$ with equimolar $\mathrm{CO}-\mathrm{Cl}_{2}$ are shown in Figure 11 . The mass loss rate increased from 0 to 175 minutes as the reactive gases penetrated the calcine bed. A constant mass loss rate was observed from 175 to 275 minutes as the calcine mass remaining in the reactor dropped from 0.80 to 0.30 grams. The reaction was complete ( $0.15 \mathrm{~g}$ calcine remaining in the reactor or $85 \%$ mass loss) after approximately seven hours.

The mass of calcine increased during the first 15 minutes of the experiment in experiments completed with zirconia calcine. No mass change occurred after 15 minutes. The overall mass loss results observed during each of the experiments completed in the fixed bed apparatus are shown in Table 16. The calcine mass decreased a maximum of $86 \%$ during chlorination of simulated alumina calcine and increased a maximum of $14 \%$ during chlorination of simulated zirconia calcine. The initial reaction rate observed for alumina calcine was 0.07 (g-calcine volatilized) / (g-calcine hour). 
Table 16

Observed Mass Loss of Chlorinated Alumina and Zirconia Calcine

\begin{tabular}{|c|c|c|c|}
\hline \hline Run \# & Calcine Type & Run Duration & \% Mass Change \\
\hline 1 & Alumina & 8 hours & -85 \\
\hline 2 & Alumina & 8 hours & -86 \\
\hline 3 & Zirconia & 4 hours & +14 \\
\hline 4 & Zirconia & 4 hours & +14 \\
\hline
\end{tabular}

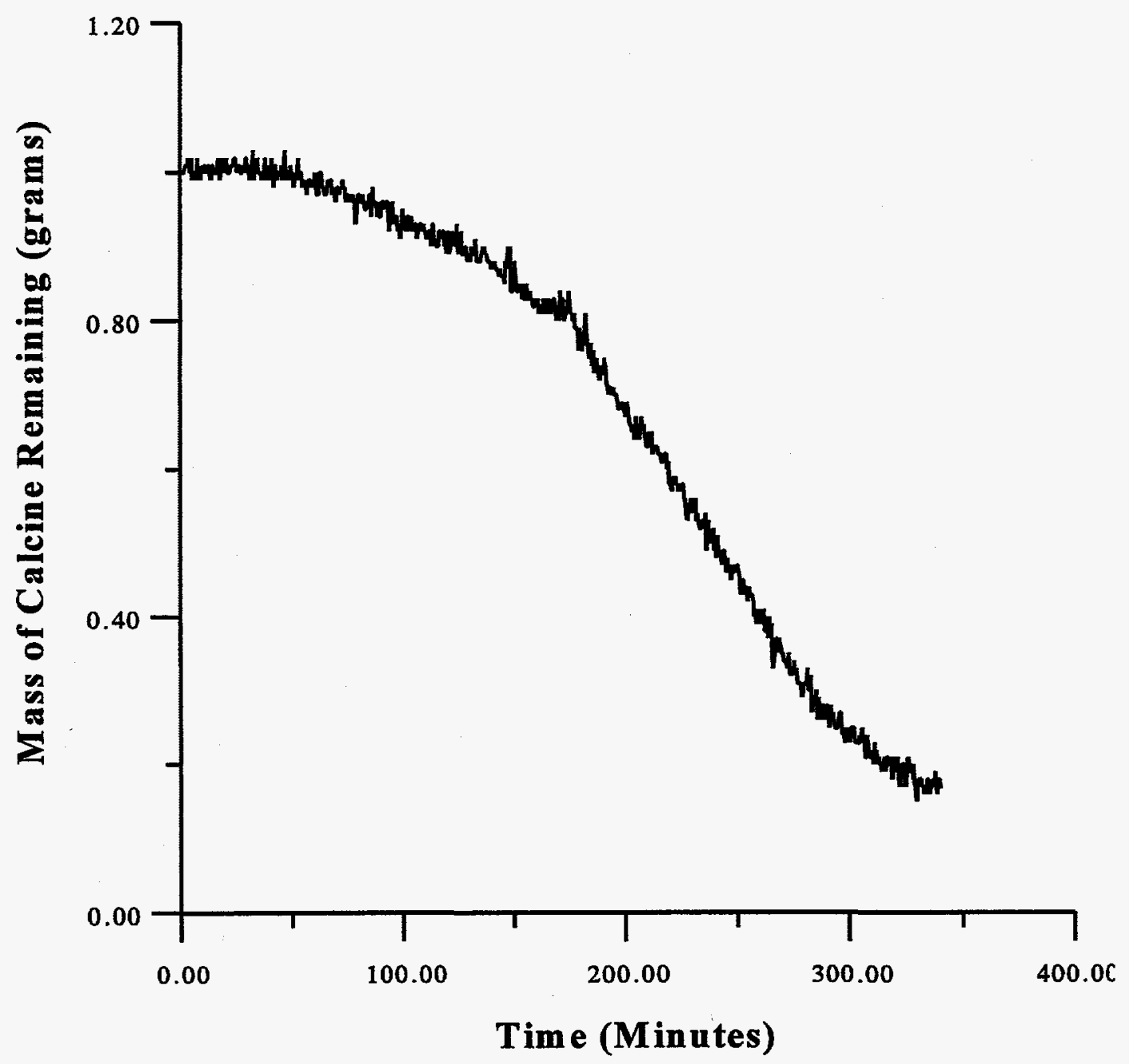

Figure 11. Measured residual mass of Run 77 (alumina) calcine during chlorination with a CO-Cl $\mathrm{Cl}_{2}$ mixture at $600^{\circ} \mathrm{C}$. 


\subsubsection{Packed-Fluidized Bed Mass Change Results for Alumina Calcine}

The results from the statistically-designed chlorination experiments completed with equimolar $\mathrm{CO}-\mathrm{Cl}_{2}$ diluted in $85 \%$ Ar are shown in Table 17 . The temperature was varied from 600 to $800^{\circ} \mathrm{C}$, the total gas flow rate was varied from 250 to $500 \mathrm{ml} / \mathrm{min}$, and the time was varied from 1 to 3 hours. Statistical analysis of the mass remaining at the end of the experiment revealed that time was the variable that affected the mass loss observed during the experimental runs, whereas the gas flow rate and temperature did not appreciably affect the calcine mass loss rate. The statistical model generated from the experimental results indicated that the maximum mass loss rate would be obtained at a temperature of $800^{\circ} \mathrm{C}$ and a total gas flow rate of $375 \mathrm{ml} / \mathrm{min}$. The reaction rate observed during the statistically designed experiments varied from 0.10 to 0.17 (g-calcine volatilized) / (g-calcine hour).

$\mathrm{CCl}_{4}$ was used as the chlorinating reagent in place of $\mathrm{CO}-\mathrm{Cl}_{2}$ to chlorinate alumina calcine in the packed/fluidized bed reactor after the statistically-designed experiments were completed. A complete listing of residual mass data collected in the packed/fluidized-bed reactor with $\mathrm{CCl}_{4}$ is shown in Appendix A. The results from chlorination experiments completed with various $\mathrm{CCl}_{4}$ mole fractions at $600^{\circ} \mathrm{C}$ are shown in Figure 12 to illustrate the effect of $\mathrm{CCl}_{4}$ mole fraction on the reaction rate. The calcine conversion appears to be linear until the conversion reaches approximately 0.50 , and then begins to decrease. Hence, the conversion rate is equal to the initial rate until the conversion is 0.50

The results from chlorination experiments completed at $500,600,700$, and $800^{\circ} \mathrm{C}$ are shown in Figure 13 to illustrate the effect of temperature on reaction rate. The initial kinetic chlorination rate constant (assuming linear chlorination rate) is plotted as a function of temperature. The rate constant increased significantly between 500 and $600^{\circ} \mathrm{C}$, and then decreased between 700 and $800^{\circ} \mathrm{C}$. The calcine chlorination rate observed with $\mathrm{CCl}_{4}$ in the temperature range studied varied between 1.44 and 11.6 (g-calcine volatilized) / (g-calcine hour). 
The results from chlorination experiments completed at various gas flow rates are shown in Figure 14 to illustrate the effect of gas flow rate on reaction rate. The calcine conversion appears to be independent of $\mathrm{CCl}_{4}$ mole fraction above 0.08 .

Table 17

Experimental Conditions Used in Statistically-Designed

Calcine Chlorination Experiments with $\mathrm{CO}-\mathrm{Cl}_{2}$

\begin{tabular}{|c|c|c|c|c|}
\hline Run \# & $\begin{array}{c}\text { Temperature of } \\
\text { Reactor }\left({ }^{\circ} \mathrm{C}\right)\end{array}$ & $\begin{array}{l}\text { Total Gas Flow } \\
\text { rate }^{*}(\mathrm{ml} / \mathrm{min})\end{array}$ & $\begin{array}{c}\text { Reaction Time } \\
\text { (hours) }\end{array}$ & $\begin{array}{c}\text { Mass Remaining } \\
\text { (grams) }\end{array}$ \\
\hline 1 & 600 & 250 & 1 & 0.84 \\
\hline 2 & 800 & 250 & 1 & 0.83 \\
\hline 3 & 600 & 500 & 1 & 0.90 \\
\hline 4 & 800 & 500 & 1 & 0.83 \\
\hline 5 & 600 & 250 & 3 & 0.74 \\
\hline 6 & 800 & 250 & 3 & 0.58 \\
\hline 7 & 600 & 500 & 3 & 0.71 \\
\hline 8 & 800 & 500 & 3 & 0.70 \\
\hline 9 & 600 & 375 & 2 & 0.76 \\
\hline 10 & 800 & 375 & 2 & 0.68 \\
\hline 11 & 700 & 250 & 2 & 0.70 \\
\hline 12 & 700 & 500 & 2 & 0.72 \\
\hline 13 & 700 & 375 & 1. & 0.89 \\
\hline 14 & 700 & 375 & 3 & 0.66 \\
\hline 15 & 700 & 375 & 2 & 0.79 \\
\hline 16 & 700 & 375 & 2 & 0.78 \\
\hline 17 & 700 & 375 & 2 & 0.73 \\
\hline 18 & 700 & 375 & 2 & 0.74 \\
\hline 19 & 700 & 375 & 2 & 0.75 \\
\hline 20 & 700 & 375 & 2 & 0.73 \\
\hline
\end{tabular}

* $20^{\circ} \mathrm{C}, 1 \mathrm{~atm}, 85 \mathrm{~mol} \% \mathrm{Ar}$ - balance equimolar $\mathrm{CO}-\mathrm{Cl}_{2}$ mixture 


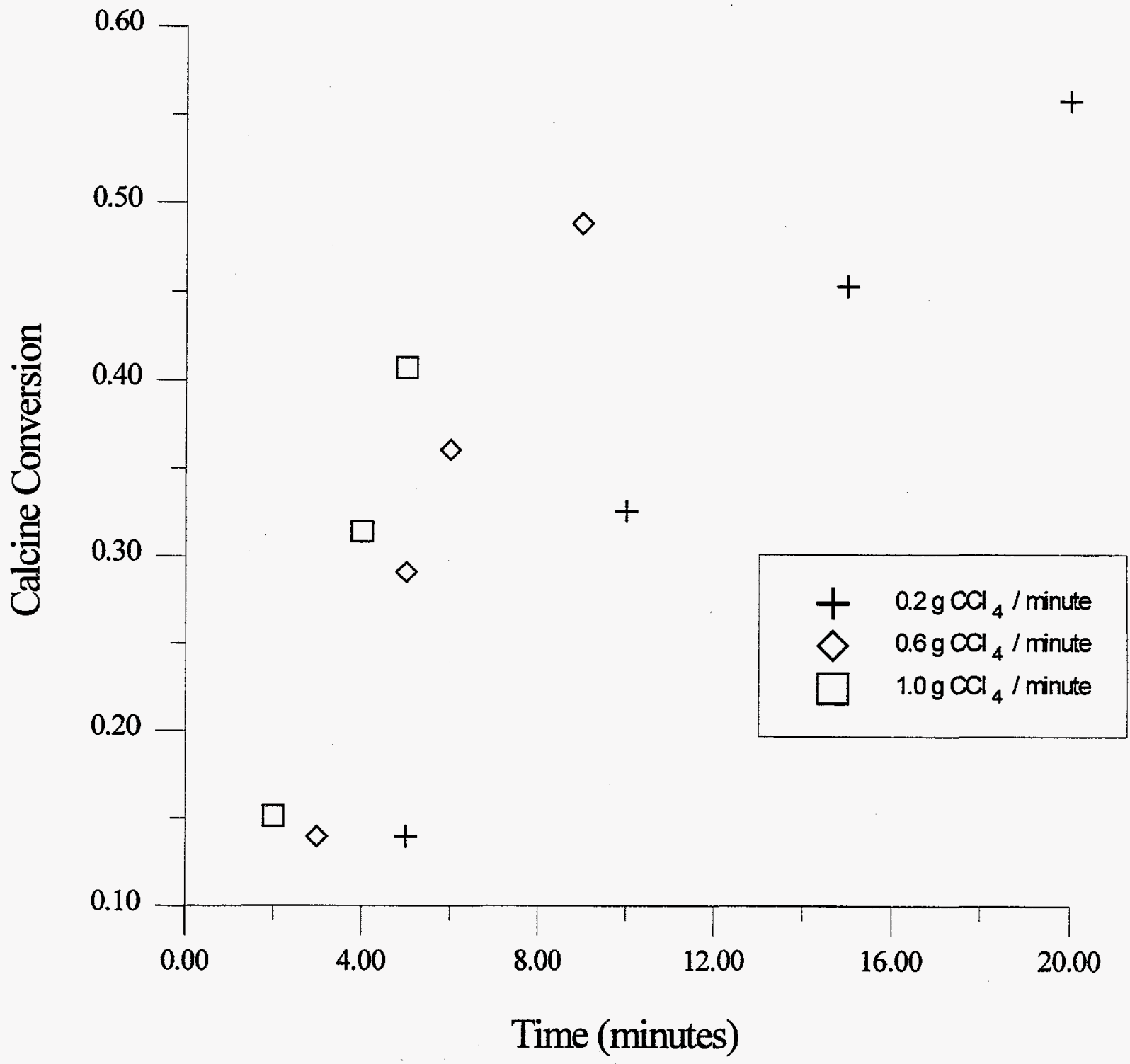

Figure 12. Conversion of calcine by chlorination with $\mathrm{CCl}_{4}$ at $500^{\circ} \mathrm{C}$ in a packed/fluidizedbed reactor setup. 


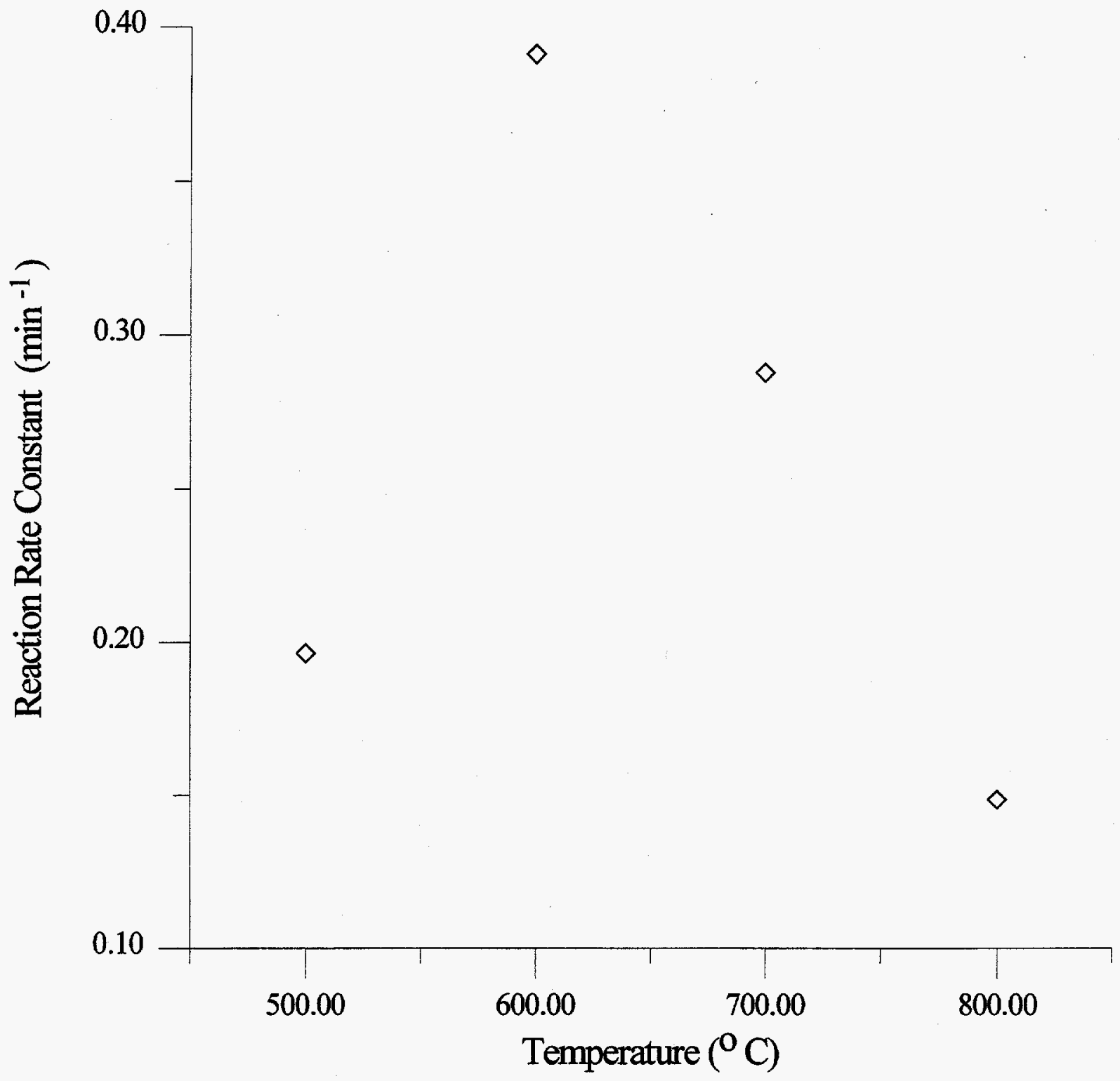

Figure 13. Reaction rate constant for the reaction of alumina calcine with $\mathrm{CCl}_{4}$ at various temperatures. 


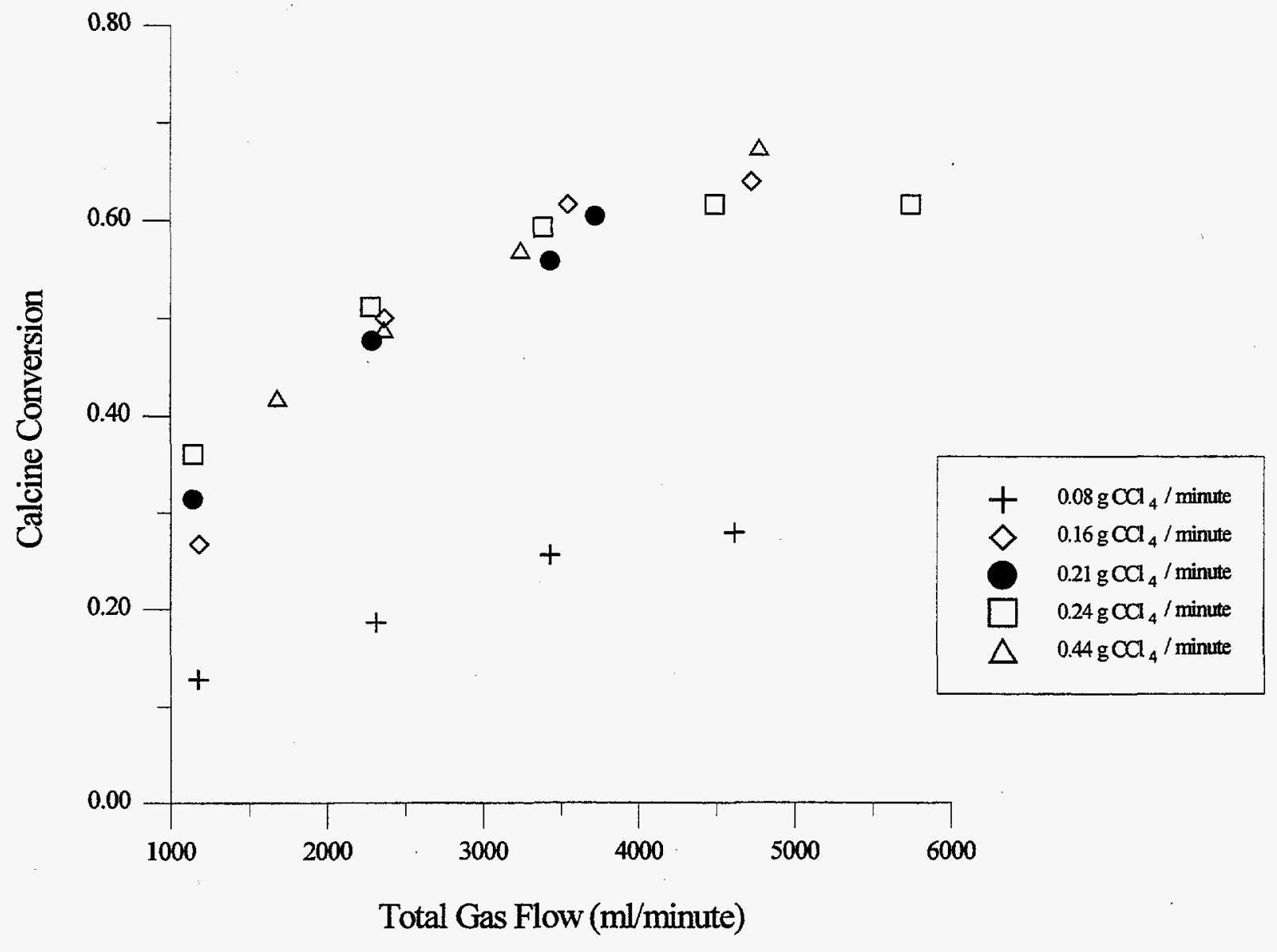

Figure 14. Conversion of calcine by chlorination with $\mathrm{CCl}_{4}$ at $600^{\circ} \mathrm{C}$ in a packed/fluidizedbed reactor. 


\subsubsection{Packed-Bed Mass Change Results for Alumina Calcine}

Initially, $\mathrm{CCl}_{4}$ was used as the chlorination reagent in the packed-bed reactor. A complete list of the experimental calcine mass loss results for the packed-bed reactor configuration is presented in Appendix B. The results from a series of chlorination experiments are shown in Figure 15 for a reactor temperature of $600^{\circ} \mathrm{C}$, a time of three minutes, and various $\mathrm{CCl}_{4}$ mole fractions as noted. Variation of the data points shown in Figure 17 was due partially to the inability to accurately meter $\mathrm{CCl}_{4}$ at the Ar flow rates tested. The reaction rate varied between 1.8 and 8.4 (g-calcine volatilized)/(g-calcine $\cdot$ hour). 


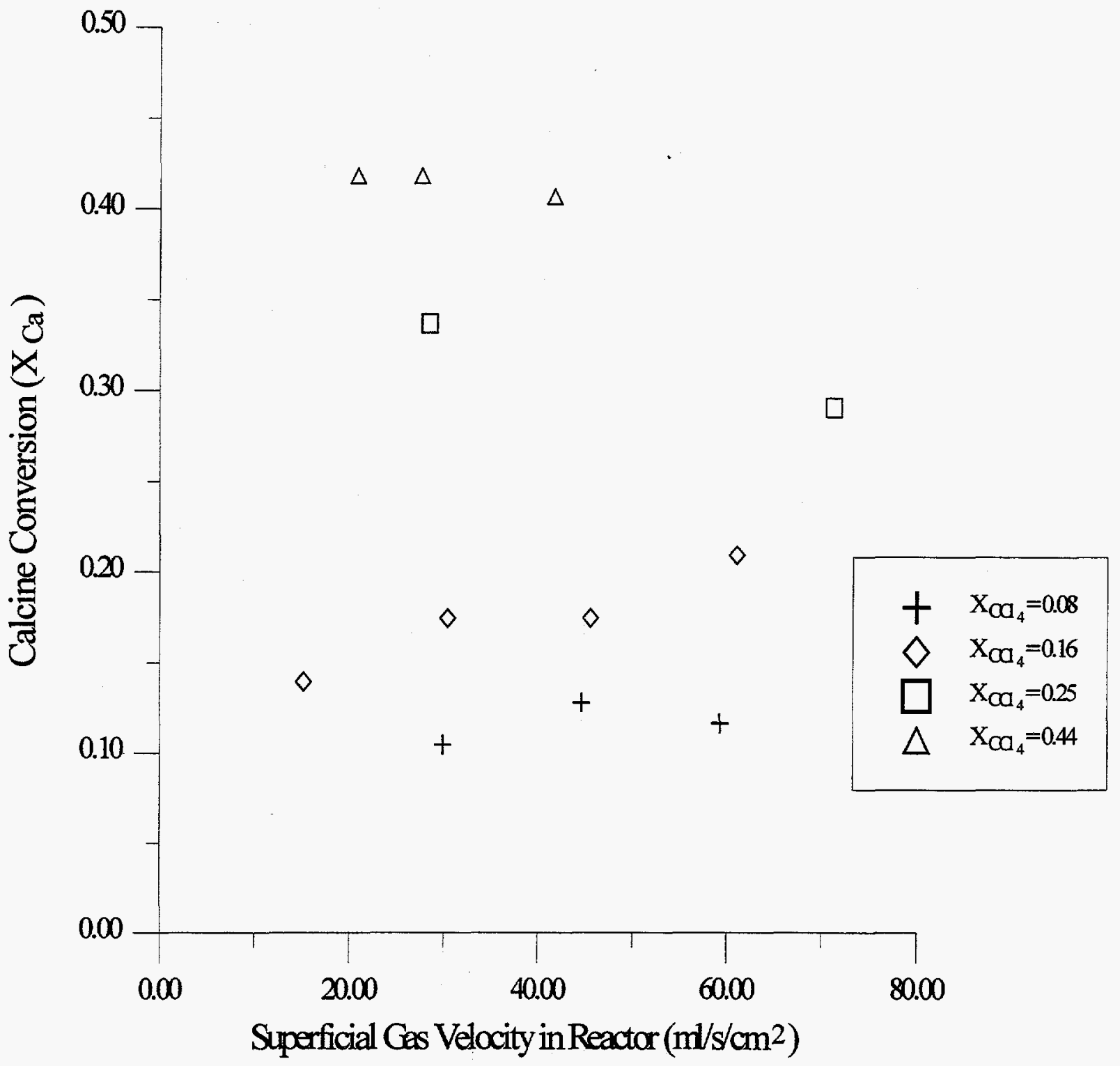

Figure 15. Conversion of calcine by chlorination with $\mathrm{CCl}_{4}$ at $600^{\circ} \mathrm{C}$ in a packed-bed reactor at various superficial reactive gas velocities.

Calcine chlorination experiments were completed in the packed-bed reactor using both a CO$\mathrm{Cl}_{2}$ mixture and $\mathrm{CCl}_{4}$ as the chlorinating reagent to determine the time required to completely chlorinate calcine and to determine experimental parameters for radioactive calcine tests. The residual calcine mass observed during these experiments is shown in Table 18. The reaction is 
complete after approximately two hours using $\mathrm{CO}-\mathrm{Cl}_{2}$ while it is nearly complete after 15 minutes using $\mathrm{CCl}_{4}$ as the chlorinating reagent.

Table 18

Mass Change of Alumina Calcine during Chlorination in a Packed Bed Reactor

\begin{tabular}{||l|l|l|l||}
\hline Run \# & Initial Mass (g) & Final Mass & Time \\
\hline $1^{*}$ & 1.00 & 0.24 & 15 Minutes \\
\hline $2^{* *}$ & 1.00 & 0.24 & 2 Hours \\
\hline $3^{* *}$ & 1.00 & 0.34 & 2 Hours $^{* * *}$ \\
\hline
\end{tabular}

Experiment completed with $\mathrm{CCl}_{4}$ as the chlorinating reagent

** Experiment completed with $\mathrm{CO}-\mathrm{Cl}_{2}$ as the chlorinating reagent

*** Carbon monoxide flow rate decreased during final 15 minutes of experiment.

The chlorination experiments with actual radioactive calcine were completed with $\mathrm{CO}-\mathrm{Cl}_{2}$ diluted in argon using the packed bed configuration due to environmental concerns with $\mathrm{CCl}_{4}$. The radioactive calcine used in the tests was made from a blend of sodium waste (liquid HLW high in sodium resulting from decontamination operations), aluminum waste (liquid HLW resulting from reprocessing aluminum-clad fuel) and non-radioactive aluminum nitrate (added to ensure efficient calcination). No analytical results for calcium or fluoride were available prior to the experiment. The mass loss observed during the chlorination experiments is shown in Table 19. The mass of calcine increased during the chlorination experiments. 
Table 19

Mass Change Results Observed During Calcine Chlorination

Experiments Completed with Actual Radioactive Calcine

\begin{tabular}{|l|l|l|l|l|l|}
\hline Run\# & $\begin{array}{l}\text { Ar Flow Rate } \\
(\mathrm{ml} / \mathrm{min})\end{array}$ & $\begin{array}{l}\text { CO Flow Rate } \\
(\mathrm{ml} / \mathrm{min})\end{array}$ & $\begin{array}{l}\mathrm{Cl}_{2} \text { Flow Rate } \\
(\mathrm{ml} / \mathrm{min})\end{array}$ & $\begin{array}{l}\text { Calcine Mass } \\
\text { Before } \\
(\mathrm{grams})\end{array}$ & $\begin{array}{l}\text { Calcine Mass } \\
\text { After (grams) }\end{array}$ \\
\hline 1 & 200 & 20 & 20 & 1.00 & 1.12 \\
\hline 2 & 200 & 20 & 20 & 1.00 & 1.09 \\
\hline Blank & 200 & 0 & 0 & 1.00 & 1.04 \\
\hline
\end{tabular}

\section{DISCUSSION}

Two considerations were considered in the investigation of calcine chlorination: 1) does a separation between radioactive and non-radioactive calcine components occur and 2) does the separation occur rapidly enough at suitable temperatures to design a process. The experimental results will be discussed to evaluate calcine chlorination on the basis of the two considerations. First, the equilibrium calculations are compared to the experimental results. Second, the chlorination kinetics are discussed and an empirical first-order rate expression is presented for the packed-bed reactor. Third, kinetic mechanistic steps are discussed and possible simplifying assumptions are presented

\subsection{Thermodynamic Equilibrium Calculations and Observed Separation Results}

Preliminary thermodynamic equilibrium calculations completed to ascertain the feasibility of calcine chlorination as a method to separate radioactive and non-radioactive alumina calcine components were not promising for zirconia calcine as no significant volatile species were predicted and the mass of calcine was predicted to increase. However, for alumina calcine, the calculation results were favorable. 


\subsubsection{Zirconia Calcine Equilibrium Calculations and Experimental Results}

Separation of radioactive and non-radioactive zirconia calcine components via chlorination was not favorable according to thermodynamic equilibrium calculations (see Table 7). The major calcine components predicted were $\mathrm{CaCl}_{2}, \mathrm{AlF}_{3}$, and $\mathrm{ZrCl}_{4}$. Other volatile species predicted during the calculations were $\mathrm{CsCl}$ and $\mathrm{UCl}_{3}$. The only major volatile species was $\mathrm{ZrCl}_{4}$. The major reaction predicted during chlorination was

$$
\mathrm{Al}_{2} \mathrm{O}_{3}+3 \mathrm{CaF}_{2}+\frac{3}{2} \mathrm{CCl}_{4}-2 \mathrm{AlF}_{3}+3 \mathrm{CaCl}_{2}+\frac{3}{2} \mathrm{CO}_{2}
$$

with a heat of reaction of $-45.5 \mathrm{kcal} /$ mole at $600^{\circ} \mathrm{C}$.

Analytical results of unreacted and reacted zirconia calcine samples showed good agreement with the equilibrium calculations except for $\mathrm{Zr}$ as no volatile reaction products were collected during chlorination experiments. X-ray diffraction completed on chlorinated zirconia calcine showed the presence of $\mathrm{AlF}_{3}$ and $\mathrm{CaClF}$ (see Table 9). $\mathrm{No}_{2} \mathrm{Al}_{3} \mathrm{O}_{3}$ was identified in either unreacted or reacted zirconia calcine samples. The EDS elemental map (see Figure 9) showed the $\mathrm{Cl}$ in close proximity with calcium indicating chlorination of $\mathrm{CaF}_{2}$ (see Equation 3).

Areas of $\mathrm{Cl}$-free zones are visible in the elemental map also. This is attributed to reaction between calcine and chlorine at the particle surface only. Reaction did not penetrate into the calcine particle further due to sintered $\mathrm{CaClF}$ at the particle surface. The melting temperature of pure $\mathrm{CaClF}$ was estimated to be $735^{\circ} \mathrm{C}$ from an equilibrium phase diagram of $\mathrm{CaF}_{2}$ and $\mathrm{CaCl}_{2}{ }^{20}$ The $\mathrm{CaClF}$ melting point may be even lower in the presence of impurities. Hence, sintering of the chlorinated zirconia calcine surface may account for the incomplete reaction observed during chlorination experiments. 
The thermodynamic calculations were inaccurate for zirconia calcine in that no $\mathrm{ZrCl}_{4}$ was identified as a reaction product in any of the experiments. This is due to both the extremely low chlorination kinetic rate of $\mathrm{ZrO}_{2}$ at $600^{\circ} \mathrm{C}$ and the sintering action of the chlorinated calcium compounds.

Mass loss was observed in chlorination experiments completed with zirconia calcine treated with $\mathrm{CaCl}_{2}$. However, $\mathrm{ZrCl}_{4}$ was not identified as a reaction product. Instead, the only major compound identified in the condensed off-gas was a degradation product of $\mathrm{CCl}_{4}, \mathrm{C}_{6} \mathrm{Cl}_{6}$. $\mathrm{Zr}$ was detected in minor quantities with $\mathrm{x}$-ray florescence. Hence, chlorination does not appear to be an effective method for separating radioactive and non-radioactive zirconia calcine components.

\subsubsection{Alumina Calcine Equilibrium Calculations and Observed Separations}

Equilibrium calculations indicated that a separation between radioactive and non-radioactive alumina calcine components was feasible. The major volatile species predicted were $\mathrm{AlCl}_{3}$, $\mathrm{BCl}_{3}, \mathrm{FeCl}_{3}, \mathrm{ZrCl}_{4}, \mathrm{UCl}_{3}$, and $\mathrm{CsCl}$ (see Table 7). Hence, two radioactive species were predicted to volatilize. The calculated components of the residual solid was unreacted $\mathrm{Al}_{2} \mathrm{O}_{3}$, $\mathrm{NaCl}$, and other unreacted oxides and non-volatile chlorides. A mass reduction of $85.5 \mathrm{wt} \%$ was predicted by the equilibrium calculations. The major chemical reaction predicted was

$$
\mathrm{Al}_{2} \mathrm{O}_{3}+\frac{3}{2} \mathrm{CCl}_{4} \rightarrow 2 \mathrm{AlCl}_{3}+\frac{3}{2} \mathrm{CO}_{2}
$$

with a $\Delta \mathrm{H}_{\mathrm{rxn}}$ of $-21.9 \mathrm{kcal} / \mathrm{mole}$ at $600^{\circ} \mathrm{C}$.

The results from SEM,EDS, and $\mathrm{x}$-ray diffraction analysis verified Equation (4) as $\mathrm{AlCl}_{3}$ was found in the off-gas samples. However, these analyses failed to indicate the presence of Cs. ICP-MS analysis of reacted calcine and condensed off-gas were necessary to detect Cs. Other volatile species detected in trace quantities with ICP-MS included Cs, Na, and Sr. However, 
only a fraction of the original mass of these trace elements was recovered in the residual solids and the condensed off-gas samples. It is possible that variations in the calcine composition or analytical error could account for the missing trace elements. Additional unit operations would be required to separate trace radioactive species (such as $\mathrm{CsCl}$ and $\mathrm{UCl}_{3}$ ) from other volatile non-radioactive components such as $\mathrm{AlCl}_{3}$ to utilize chlorination as a treatment method for alumina calcine.

\subsection{Alumina Calcine Chlorination Kinetics}

The reaction rate observed during alumina calcine chlorination experiments was dependent on chlorinating reagent, reactant gas flow, reactant gas concentration, reactor configuration, and temperature. A parametric study was completed in an effort to develop an overall kinetic rate expression. General correlations between some experimental parameters and the reaction rate were found. However, the effect of some experimental parameters on the reaction rate defied simple explanation. The effect of each experimental parameter on reaction rate and formulation of a kinetic model are discussed below.

\subsubsection{Temperature Effects and Activation Energy}

The effect of temperature on the reaction rate constant typically follows the Arrhenius Law. The activation energy calculated with the Arrhenius law between 500 and $600^{\circ} \mathrm{C}$ for alumina calcine chlorination was $6.7 \mathrm{kcal} / \mathrm{mole}$. This is much lower than the literature-reported values for reaction of $\mathrm{Al}_{2} \mathrm{O}_{3}$ and bauxite ore with various mixtures of $\mathrm{C}-\mathrm{Cl}_{2}$ and $\mathrm{CO}-\mathrm{Cl}_{2}$ diluted in $\mathrm{Ar}$ (see Section 2.1). The rate constant observed during chlorination experiments did not follow the Arrhenius Law over the entire temperature range studied (see Figure 13). The failure of the Arrhenius Law to describe the effect of temperature on the reaction rate constant was due to four major causes: 1) a shifting reaction mechanism over the wide temperature range studied, 2) the $\alpha-\mathrm{Al}_{2} \mathrm{O}_{3}$ phase transition, 3) $\mathrm{CCl}_{4}$ decomposition, and 4) increasing effect of 
mass-transfer resistance with increasing temperature. The shifting reaction mechanism is consistent with results reported in the literature for $\mathrm{Al}_{2} \mathrm{O}_{3}$ chlorination.

Alumina calcine consists of several $\mathrm{Al}_{2} \mathrm{O}_{3}$ phases including relatively chlorination-resistant $\alpha$ $\mathrm{Al}_{2} \mathrm{O}_{3}$. The fraction of $\alpha-\mathrm{Al}_{2} \mathrm{O}_{3}$ in the calcine increases during chlorination due to three main causes. First, reactive $\mathrm{Al}_{2} \mathrm{O}_{3}$ phases are chlorinated and volatilized. Second, the phase transformation of subphases of $\mathrm{Al}_{2} \mathrm{O}_{3}$ to $\alpha-\mathrm{Al}_{2} \mathrm{O}_{3}$ at temperatures much lower than the typical phase transformation temperature $\left(1050^{\circ} \mathrm{C}\right.$ ) in the presence of impurities (see Reference 3). Third, the heat of reaction (see Equation 4) increases the calcine surface temperature enough to allow the $\alpha-\mathrm{Al}_{2} \mathrm{O}_{3}$ phase transition to occur (see Reference 3). Detailed calcine surface temperature measurements and phase transformation temperature studies would be required to verify this theory.

As the temperature of the bulk gas increases, the amount of $\mathrm{CCl}_{4}$ decomposing prior to calcine chlorination increases. Hence, as the temperature is increased, the concentration of $\mathrm{CCl}_{4}$ reaching the calcine particle decreases.

\subsubsection{Reactor Configuration Effects}

The alumina calcine chlorination rate was different in each of the experimental reactor configurations tested. The fastest chlorination rates were observed in the packed/fluidized-bed configuration and the slowest rates were observed in the fixed-bed configuration. The difference in rates observed in the different reactors is due to the transport of reactant gas to the stagnant gas boundary layer surrounding the particle. Several models were evaluated in an effort to develop a theoretical kinetic model. 


\subsection{Alumina Calcine Chlorination Reaction Mechanisms and Kinetic Model.}

There are 10 mechanistic steps (see Section 3.2) which could affect calcine chlorination kinetics. These mechanistic steps (resistances to reaction) and an empirical kinetic model for the observed data in the packed/fluidized-bed and packed-bed reactor are discussed below.

\subsubsection{Packed/Fluidized-Bed Reaction Kinetics}

The development of an overall theoretical rate expression for alumina calcine is not practical at this stage of investigation. Of the 10 possible reaction mechanisms identified, five to six . could be included in formulating the overall rate expression. To include these five mechanisms in the overall rate expression the following parameters must be measured experimentally: Thiele modulus, $\mathrm{D}_{\mathrm{e}}, \mathrm{k}_{\mathrm{ads}}, \mathrm{k}_{\mathrm{rxn}}, \mathrm{CCl}_{4}$ decomposition, and the physical and transport properties for the $\mathrm{CCl}_{4}$-Ar system.

The resistance of bulk gas diffusion on the reaction rate was demonstrated in experiments completed in the packed/fluidized bed. The effect of bulk gas diffusion on reaction rate was diminished as the flow rate of reactive gas was increased (see Figure 16) above $3500 \mathrm{ml} / \mathrm{min}$. Flow rates higher than $3500 \mathrm{ml} / \mathrm{min}$ did not change the chlorination rate.

The reaction rate was not a function of reactant gas mole fraction at higher gas flow rates and $\mathrm{CCl}_{4}$ mole fractions above 0.16 (see Figure 14) in the packed/fluidized bed. Further increases in reaction rate were not observed at $\mathrm{CCl}_{4}$ mole fractions as high as 0.44 . This may be due to control of the reaction rate by a Langmuir-Hinshelwood mechanism. Once all available adsorption sites are occupied, higher concentrations of reactant gases (such as $\mathrm{CCl}_{4}$ ) will not increase the reaction rate. An alternative cause for the constant reaction rate at high $\mathrm{CCl}_{4}$ mole fractions could be carry-over of small particulates in the off-gas. Larger-scale reactors would need to be tested to verify the reaction kinetics observed in the packed-fluidized bed reactor to complete scale-up of this process. 


\subsubsection{Packed-Bed Reactor Kinetics}

The discussion presented for kinetic effects in the packed/fluidized bed reactor is applicable to the kinetic effects observed in the packed-bed reactor with the exception of the bulk gas diffusion resistance. The reaction rate was not influenced by the bulk gas flow rate. Hence, this effect would not be included in a theoretical reaction expression for the packed-bed reactor.

The kinetic results from experiments completed in a packed-bed reactor setup showed a dependence on the reactant concentration (or reactant gas mole fraction), and a first-order rate expression was applied to the results. A plot of the kinetic results from packed-bed reactor experiments is shown in Figure 16. The first-order rate fit (see Equation 2) gives a correlation coefficient of 0.98 . The first-order rate fit appears to provide an adequate model for the chlorination kinetics observed in a packed-bed reactor. 


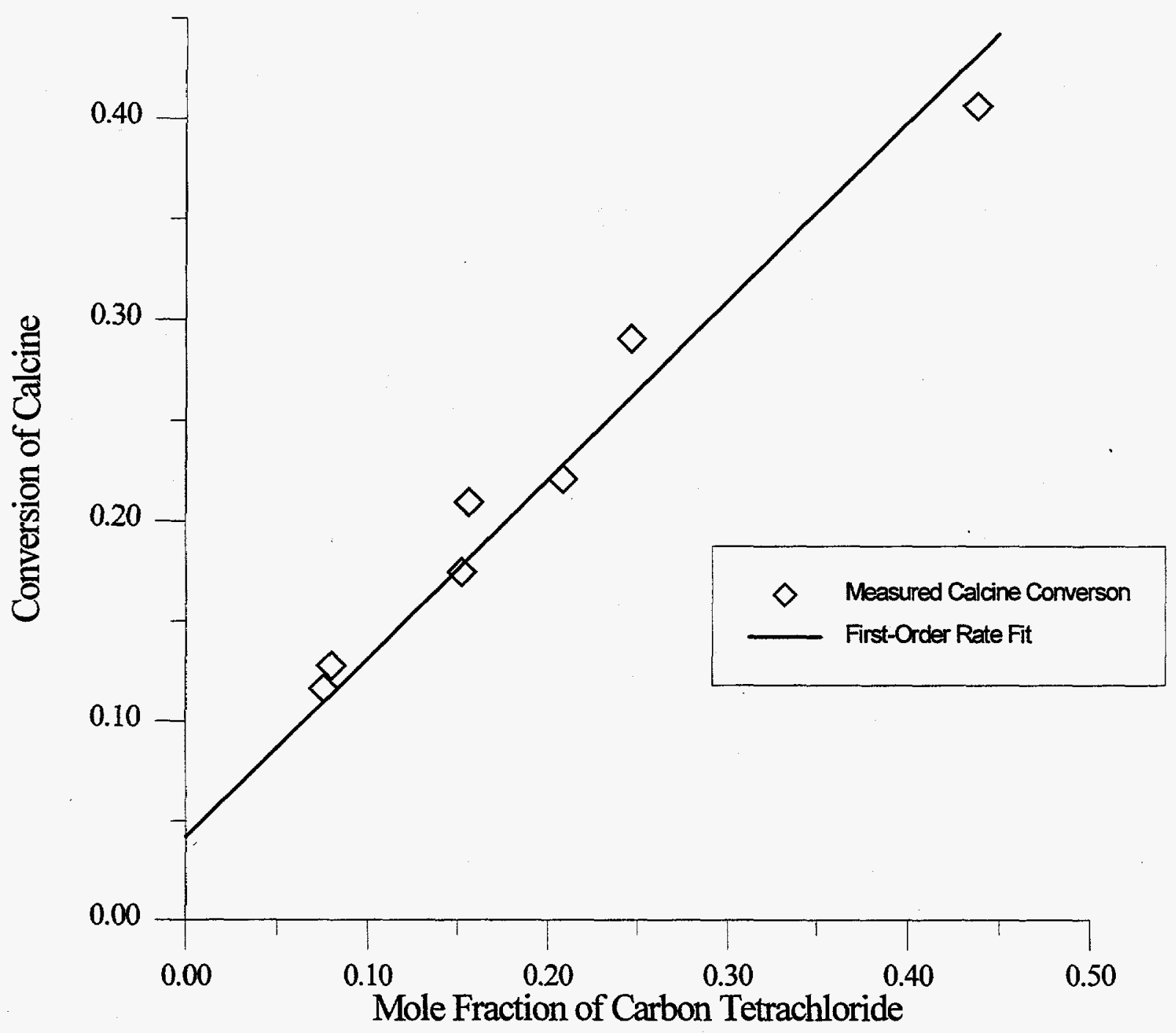

Figure 16. Alumina calcine conversion observed during experiments completed in a packedbed reactor with carbon tetrachloride at $600^{\circ} \mathrm{C}$. 


\section{CONCLUSIONS AND RECOMMENDATIONS}

Based on the calcine chlorination experimental work conclusions and recommendations are made. The conclusions are:

1- The thermodynamic equilibrium calculations completed on $\mathrm{F}^{*} \mathrm{~A}^{*} \mathrm{C}^{*} \mathrm{~T}^{*}$ showed good agreement with experimental results.

2- An empirical first-order reaction expression provided a good model of calcine chlorination kinetics in a packed-bed reactor

3- The calcine chlorination rate was approximately eight times faster with $\mathrm{CCl}_{4}$ as compared to $\mathrm{CO} / \mathrm{Cl}_{2}$.

4- Several kinetic mechanisms influence the rate of alumina calcine chlorination: bulk gas diffusion, pore diffusion, adsorption of reactant gas at the solid surface, decomposition or reaction of reactant gas, and chemical reaction at the surface. Diffusion through the ash layer did not affect the kinetic rate.

5- Chlorination of alumina calcine yields a separation of some calcine components. However, chlorination does not result in a clean separation of radioactive and nonradioactive calcine components at temperatures above $600^{\circ} \mathrm{C}$.

6- Chlorination of zirconia calcine results in a mass increase and no separation between calcine components occurs.

The following recommendations are made for future calcine chlorination investigations:

1- Measure the following calcine properties: Thiele modulus, $\mathrm{D}_{\mathrm{e}}, \mathrm{k}_{\mathrm{dds}}, \mathrm{k}_{\mathrm{rx}}, \mathrm{k}_{\mathrm{des}}$, and $\mathrm{CCl}_{4}$ decomposition and/or $\mathrm{CO} / \mathrm{Cl}_{2}$ gas phase reaction.

2- Measure the following physical and transport reactive gas $\left(\mathrm{CCl}_{4}-\mathrm{Ar}\right.$ and $\left.\mathrm{CO} / \mathrm{Cl}_{2}-\mathrm{Ar}\right)$ properties: viscosity, binary diffusion coefficient, density.

3- Complete additional chlorination experiments to optimize the chlorination temperature with respect to kinetics and radioactive/non-radioactive component separation.

4- Investigate methods to remove trace radioactive chlorides from non-radioactive chlorides. 
5- Complete surface temperature measurements to ensure that the bulk temperature measured in the reactor accurately represents the actual surface temperature of the calcine particle.

6- Complete $\mathrm{Al}_{2} \mathrm{O}_{3}$ phase transition studies at the surface temperature measured during chlorination experiments.

7- Recommended alumina calcine chlorination reactor configuration and parameters are: fluidized-bed reactor configuration (maximum rate), reactor temperature of $600^{\circ} \mathrm{C}$ (maximum rate), and $\mathrm{CCl}_{4}$ as the reactant gas. If necessary, a packed bed of calcine could be used to deplete the residual $\mathrm{CCl}_{4}$ in the fluidized reactor. The calcine in the packed bed could be batch-fed to the fluidized bed counter-current to the effluent gas flow. 


\section{REFERENCES}

1- J. R. Berreth, Inventories and Properties of ICPP Calcined High-Level Waste. WINCO1050 (February, 1988).

2- Del Debbio, J. A., Removal of Cesium from High-Level Calcined Waste by High Temperature Volatilization. INEL-94/0028, October, 1994.

3- D. J. Milne, The Chlorination of Alumina and Bauxite with Chlorine and Carbon Monoxide. Proc. Australas. Inst. Min. Metall., No. 260, December, 1976, ppg. 23-31.

4- Treadwell, W. D., and Terebesi, L., Zur Kenntnis der Chlorierung von Aluminiumoxyd mit Chlor und Kohlenoxyd. Helvetica Chimica Acta, Volumen XV, ppg. 1353-1362, 1932.

5- A. Landsberg, Chlorination Kinetics of Aluminum Bearing Minerals, Metallurgical Transactions B, Vol. 6B, June, 1975, ppg. 207-214.

6- Mark, H. F., Othmer, D. F., Overberger, C. G., Seaborg, G. T., Kirk-Othmer Encyclopedia of Chemical Technology, 3rd edi., vol. 2, John Wiley \& Sons, ppg. 209244.

7- Mark, H. F., Othmer, D. F., Overberger, C. G., Seaborg, G. T., Kirk-Othmer Encyclopedia of Chemical Technology, 3rd edi., vol. 24, John Wiley \& Sons, ppg. 863902.

8- Landsberg, A., Hoatson, C. L., Block, F. E., The Chlorination Kinetics of Zirconium Dioxide in the Presence of Carbon and Carbon Monoxide, Metallurgical Transactions, Vol. 3, Feb. 1972, ppg. 517-523.

9- Bullard, J. E. and Petchul, J. J., Diversion Resistance of a Chloride Volatility Reprocessing System for $\mathrm{UO}_{2} / \mathrm{ThO}_{2}$ Fuel, Journal of the American Ceramic Society, Vol. 63, No. 7-8, July-August, 1980.

10- West, M. H., Ferran, M. D., Fife, K. W., The Chlorination of Plutonium Dioxide. LA11256, UC-711, September, 1988.

11- Taylor, P. H., Dellinger, B., Thermal Degradation Characteristics of Chloromethane Mixtures, Environ. Sci. Technol., 1988, 22 ppg. 438-447.

12- Kanunnikov, Chlorination of Molybdenum Trioxide by Carbon Tetrachloride, Applied Chemistry of the USSR, vol. 59, No. 8, Part 1, August, 1986, ppg. 1564-1567. 
13- Gaisinovich, M. S., Ketov, A. N., Infrared Spectrophotometric Study of Thermal Decomposition of $\mathrm{CCl}_{4}$ under Static Conditions, Translated from Zhurnal Prikladnoi Khimii, Vol. 44, No. 5, ppg. 1079-1084, May, 1971.

14- Thompson, W. T., Pelton, A. D., Bale, C. W., Facilities for the Analysis of Chemical Thermodynamics Guide to Operations, 1985.

15- Levenspiel, O., Chemical Reaction Engineering, John Wiley \& Sons, second edition, 1972, ppg. 357-377.

16- Bird, R. B., Stewart, W. E., Lightfoot, E. N., Transport Phenomena, John Wiley \& Sons, 1960, ppg. 411, 646-647.

17- Kunii, D., Levenspiel, O., Fluidization Engineering, Robert E. Krieger Publishing Company, Huntington, NY, 1977.

18- Smith, J. M., Chemical Engineering Kinetics, McGraw-Hill, 1981, ppg. 642-644.

19- Carberry, J. J., Chemical and Catalytic Reaction Engineering. McGraw-Hill, 1976, ppg. 382388.

20- Wenz, D. A., Johnson, I., Wolson, R. D., $\mathrm{CaCl}_{2}-\mathrm{Rich}$ Region of the $\mathrm{CaCl}_{2} \mathrm{CaF}_{2} \mathrm{CaO}$ System. Journal of Chemical and Engineering Data, 14 [2], ppg. 250-252, 1969 
Appendix A

Table A.1

Experimental Raw Data from Calcine Chlorination Experiments Completed in a Packed/Fluidized Bed Reactor

\begin{tabular}{|c|c|c|c|c|c|c|c|}
\hline$\overline{\overline{\text { Run \# }}}$ & $\overline{\mathrm{T}_{\text {reactor }}}$ & $\begin{array}{l}\text { Reaction } \\
\text { Time (min) }\end{array}$ & $\begin{array}{c}\text { Argon Gas } \\
\text { Flow Rate } \\
(\mathrm{ml} / \mathrm{min})\end{array}$ & $\begin{array}{c}\mathrm{M}_{\mathrm{CCl} 4}^{\mathrm{o}} \\
(\mathrm{g})\end{array}$ & $\begin{array}{c}\mathrm{M}_{\mathrm{CCl} / 4}^{\mathrm{f}} \\
(\mathrm{g})\end{array}$ & $\begin{array}{c}\mathrm{M}_{\text {Calcine }}^{\circ} \\
(\mathrm{g})\end{array}$ & $\begin{array}{c}\bar{M}_{\text {Calcine }}^{f} \\
\text { (g) }\end{array}$ \\
\hline 1 & 600 & 1 & 200 & -1.93 & -2.54 & 1 & 0.92 \\
\hline 2 & 600 & 2 & 200 & -0.59 & -1.78 & 1 & 0.85 \\
\hline 3 & 600 & 3 & 200 & -0.57 & -2.36 & 1 & 0.79 \\
\hline 4 & 600 & 4 & 200 & -3.14 & -5.51 & 1 & 0.72 \\
\hline 5 & 600 & 5 & 200 & -0.59 & -3.58 & 1 & 0.65 \\
\hline 6 & 600 & 1 & 200 & -0.61 & -1.65 & 1 & 0.90 \\
\hline 7 & 600 & 2 & 200 & -0.68 & -2.75 & 1 & 0.74 \\
\hline 8 & 600 & 3 & 200 & -6.41 & -9.48 & 1 & 0.62 \\
\hline 9 & 600 & 4 & 200 & -0.80 & -4.82 & 1 & 0.52 \\
\hline 10 & 600 & 6 & 200 & -1.46 & -7.78 & 1 & 0.30 \\
\hline 11 & 600 & 2 & 200 & -0.21 & -0.64 & 1 & 0.93 \\
\hline 12 & 600 & 4 & 200 & -0.16 & -0.82 & 1 & 0.92 \\
\hline 13 & 600 & 4 & 200 & -2.75 & -6.68 & 1 & 0.6 \\
\hline 14 & 600 & 3 & 200 & -8.23 & -11.16 & 1 & 0.68 \\
\hline 15 & 600 & 2 & 200 & -1.93 & -3.86 & 1 & 0.79 \\
\hline 16 & 600 & 1 & 200 & -5.3 & -6.28 & 1 & 0.90 \\
\hline 17 & 600 & 4 & 200 & -1.82 & -5.61 & 1 & 0.59 \\
\hline 18 & 600 & 3 & 200 & $\begin{array}{r}-7.09 \\
\end{array}$ & -9.93 & 1 & 0.67 \\
\hline 19 & 600 & 2 & 200 & -7.48 & -9.48 & 1 & 0.79 \\
\hline 20 & 600 & 3 & 300 & -2.97 & -7.18 & 1 & 0.64 \\
\hline 21 & 600 & 3 & 400 & -0.46 & -6.72 & 1 & 0.58 \\
\hline 22 & 600 & 3 & 600 & -2.39 & -10.16 & 1 & 0.51 \\
\hline 23 & 600 & 3 & 800 & 0 & -12.1 & 1 & 0.42 \\
\hline 24 & 600 & 2 & 275 & 0 & -1.05 & 1 & 0.82 \\
\hline 25 & 600 & 4 & 275 & 0 & -2.33 & 1 & 0.58 \\
\hline 26 & 600 & 6 & 275 & 0 & -3.55 & 1 & 0.39 \\
\hline 27 & 600 & 3 & 275 & 0 & -1.73 & 1 & 0.69 \\
\hline 28 & 600 & 3 & 550 & 0 & -3.42 & 1 & 0.56 \\
\hline 29 & 600 & 3 & 825 & 0 & -4.98 & 1 & 0.49 \\
\hline 30 & 600 & 3 & 1100 & 0 & -6.55 & 1 & 0.47 \\
\hline 31 & 600 & 3 & 1375 & 0 & -8.88 & 1 & 0.47 \\
\hline 32 & 600 & 2 & 351 & 0 & -0.46 & 1 & 0.94 \\
\hline 33 & 600 & 4 & 351 & 0 & -0.81 & 1 & 0.84 \\
\hline
\end{tabular}


Table A.1 (continued)

\begin{tabular}{|c|c|c|c|c|c|c|c|}
\hline 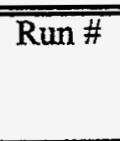 & 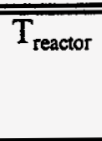 & $\begin{array}{c}\text { Reaction } \\
\text { Time (min) }\end{array}$ & $\begin{array}{c}\text { Argon Gas } \\
\text { Flow Rate } \\
(\mathrm{ml} / \mathrm{min})\end{array}$ & $\begin{array}{c}\mathrm{M}_{\mathrm{CCl} / 4}^{\mathrm{o}} \\
(\mathrm{g})\end{array}$ & $\begin{array}{c}\mathrm{M}_{\mathrm{CCl} 4}^{f} \\
(\mathrm{~g})\end{array}$ & $\begin{array}{c}\mathbf{M}_{\text {Calcine }}^{0} \\
(\mathrm{~g})\end{array}$ & $\begin{array}{c}\mathrm{M}_{\text {Calcine }}^{\mathrm{f}} \\
(\mathrm{g})\end{array}$ \\
\hline 34 & 600 & 6 & 351 & 0 & -1.3 & 1 & 0.73 \\
\hline 35 & 600 & 3 & 351 & 0 & -0.70 & 1 & 0.89 \\
\hline 36 & 600 & 3 & 351 & 0 & -1.12 & 1 & 0.79 \\
\hline 37 & 600 & 3 & 351 & 0 & -1.67 & 1 & 0.71 \\
\hline 38 & 600 & 3 & 1404 & -7.9 & -10.3 & 1 & 0.76 \\
\hline 39 & 600 & 3 & 702 & 0 & -1.22 & 1 & 0.84 \\
\hline 40 & 600 & 3 & 1053 & -3.43 & -5.05 & 1 & 0.78 \\
\hline 41 & 600 & 1 & 1404 & 0 & -0.73 & 1 & 0.97 \\
\hline 42 & 600 & 2 & 1404 & 0 & -1.48 & 1 & 0.91 \\
\hline 43 & 600 & 4 & 1404 & 0 & -2.96 & 1 & 0.69 \\
\hline 44 & 600 & 1 & 1404 & 0 & -1.53 & 1 & 0.88 \\
\hline 45 & 600 & 1 & 1270 & 0 & -1.71 & 1 & 0.83 \\
\hline 46 & 600 & 2 & 1270 & 0 & NR (-3) & 1 & 0.67 \\
\hline 47 & 600 & 3 & 1270 & 0 & -4.65 & 1 & 0.52 \\
\hline 48 & 600 & 4 & 1270 & 0 & -6.14 & 1 & 0.42 \\
\hline 49 & 600 & 1 & 1135 & 0 & -1.93 & 1 & 0.89 \\
\hline 50 & 600 & 2 & 1135 & 0 & -4.38 & 1 & 0.54 \\
\hline 51 & 600 & 4 & 1135 & 0 & -9.06 & 1 & 0.31 \\
\hline 52 & 600 & 3 & 423 & 0 & -1.47 & 1 & 0.73 \\
\hline 53 & 600 & 3 & 846 & 0 & -2.74 & 1 & 0.59 \\
\hline 54 & 600 & 3 & 1387 & 0 & -4.89 & 1 & 0.48 \\
\hline 55 & 600 & 3 & 900 & 0 & -25.74 & 1 & 0.31 \\
\hline 56 & 600 & 3 & 1000 & 0 & -14.72 & 1 & 0.38 \\
\hline 57 & 600 & 3 & 300 & 0 & -4.33 & 1 & 0.37 \\
\hline 58 & 600 & 3 & 400 & 0 & -5.85 & 1 & 0.34 \\
\hline 59 & 600 & 3 & 600 & 0 & -8.75 & 1 & 0.31 \\
\hline 60 & 600 & 3 & 800 & 0 & -11.72 & 1 & 0.38 \\
\hline 61 & 600 & 1 & 1320 & 0 & -1.52 & 1 & 0.85 \\
\hline 62 & 600 & 2 & 1320 & 0 & -3.05 & 1 & 0.66 \\
\hline 63 & 600 & 3 & 1320 & 0 & -4.80 & 1 & 0.45 \\
\hline 64 & 600 & 4 & 1.320 & 0 & -6.16 & 1 & 0.34 \\
\hline 65 & 600 & 3 & 330 & 0 & -1.21 & 1 & 0.77 \\
\hline 66 & 600 & 2 & 660 & 0 & -1.62 & 1 & 0.76 \\
\hline 67 & 600 & 3 & 990 & 0 & -3.60 & 1 & 0.47 \\
\hline 68 & 600 & 3 & 660 & 0 & -2.34 & 1 & 0.57 \\
\hline 69 & 600 & 1 & 1320 & 0 & -1.59 & 1 & 0.91 \\
\hline 70 & 600 & 2 & 1320 & 0 & -2.96 & 1 & 0.78 \\
\hline 71 & 600 & 3 & 1320 & 0 & -4.23 & 1 & 0.48 \\
\hline 72 & 600 & 4 & 1320 & 0 & -6.26 & 1 & 0.42 \\
\hline
\end{tabular}


Table A.1 (continued)

\begin{tabular}{|c|c|c|c|c|c|c|c|}
\hline$\overline{\overline{\text { Run \# }}}$ & $\mathrm{T}_{\text {reactor }}$ & $\begin{array}{c}\text { Reaction } \\
\text { Time (min) }\end{array}$ & $\begin{array}{c}\text { Argon Gas } \\
\text { Flow Rate } \\
(\mathrm{ml} / \mathrm{min})\end{array}$ & $\begin{array}{c}\mathrm{M}_{\mathrm{CCl} 4}^{\circ} \\
(\mathrm{g})\end{array}$ & $\begin{array}{c}\mathrm{M}_{\mathrm{CCl} 4}^{\mathrm{f}} \\
(\mathrm{g})\end{array}$ & $\begin{array}{c}\mathrm{M}_{\text {Calcine }}^{\circ} \\
(\mathrm{g})\end{array}$ & $\begin{array}{c}\mathrm{M}_{\text {Calcine }}^{\mathrm{f}} \\
(\mathrm{g})\end{array}$ \\
\hline 73 & 600 & 3 & 330 & 0 & -1.25 & 1 & 0.81 \\
\hline 74 & 600 & 3 & 660 & 0 & -2.43 & 1 & 0.67 \\
\hline 75 & 600 & 3 & 990 & 0 & -3.62 & 1 & 0.51 \\
\hline 76 & 600 & 5 & 100 & 0 & NR $(-1)$ & 1 & 0.78 \\
\hline 77 & 600 & 10 & 100 & 0 & NR $(-2)$ & 1 & 0.54 \\
\hline 78 & 600 & 15 & 100 & 0 & NR (-3) & 1 & 0.29 \\
\hline 79 & 600 & 20 & 100 & 0 & NR (-4) & 1 & 0.14 \\
\hline 80 & 600 & 1 & 100 & 0 & -0.57 & 1 & 0.91 \\
\hline 81 & 600 & 2 & 100 & 0 & -1.14 & 1 & 0.78 \\
\hline 82 & 600 & 3 & 100 & 0 & -1.76 & 1 & 0.65 \\
\hline 83 & 600 & 4 & 100 & 0 & -2.44 & 1 & 0.58 \\
\hline 84 & 600 & 5 & 100 & 0 & -3.17 & 1 & 0.41 \\
\hline 85 & 600 & 6 & 100 & 0 & -3.92 & 1 & 0.33 \\
\hline 86 & 600 & 7 & 100 & 0 & -4.44 & 1 & 0.27 \\
\hline 87 & 600 & 8 & 100 & 0 & -4.94 & 1 & 0.24 \\
\hline 88 & 600 & 9 & 100 & 0 & -5.16 & 1 & 0.19 \\
\hline 89 & 600 & 10 & 100 & 0 & -6.06 & 1 & 0.15 \\
\hline 90 & 600 & 11 & 100 & 0 & -6.36 & 1 & 0.12 \\
\hline 91 & 600 & 12 & 100 & 0 & -7.02 & 1 & 0.16 \\
\hline 92 & 700 & 1 & 100 & 0 & -0.60 & 1 & 0.94 \\
\hline 93 & 700 & 2 & 100 & 0 & -1.26 & 1 & 0.83 \\
\hline 94 & 700 & 3 & 100 & 0 & -1.81 & 1 & 0.78 \\
\hline 95 & 700 & 4 & 100 & 0 & -2.22 & 1 & 0.7 \\
\hline 96 & 700 & 5 & 100 & 0 & -2.92 & 1 & 0.64 \\
\hline 97 & 700 & 6 & 100 & 0 & -3.61 & 1 & 0.6 \\
\hline 98 & 700 & 7 & 100 & 0 & -4.34 & 1 & 0.5 \\
\hline 99 & 700 & 8 & 100 & 0 & -4.91 & 1 & 0.47 \\
\hline 100 & 700 & 10 & 100 & 0 & -6.06 & 1 & 0.41 \\
\hline 101 & 700 & 2 & 100 & 0 & -1.87 & 1 & 0.7 \\
\hline 102 & 700 & 4 & 100 & 0 & -3.77 & 1 & 0.44 \\
\hline 103 & 700 & 6 & 100 & 0 & -5.59 & 1 & 0.18 \\
\hline 104 & 700 & 12 & 100 & 0 & -7.38 & 1 & 0.26 \\
\hline 105 & 700 & 14 & 100 & 0 & -8.55 & 1 & 0.2 \\
\hline 106 & 700 & 16 & 100 & 0 & NR $(-9.6)$ & 1 & 0.13 \\
\hline 107 & 700 & 5 & 100 & 0 & -0.97 & 1 & 0.87 \\
\hline 108 & 700 & 10 & 100 & 0 & -1.91 & 1 & 0.75 \\
\hline 109 & 700 & 15 & 100 & 0 & -2.19 & 1 & 0.63 \\
\hline 110 & 700 & 20 & 100 & 0 & -3.92 & 1 & 0.51 \\
\hline 111 & 800 & 5 & 100 & 0 & -4.65 & 1 & 0.67 \\
\hline
\end{tabular}


Table A.1 (continued)

\begin{tabular}{|c|c|c|c|c|c|c|c|}
\hline Run \# & $\overline{T_{\text {reactor }}}$ & $\begin{array}{l}\text { Reaction } \\
\text { Time (min) }\end{array}$ & $\begin{array}{c}\text { Argon Gas } \\
\text { Flow Rate } \\
(\mathrm{ml} / \mathrm{min})\end{array}$ & $\begin{array}{c}\mathbf{M}_{\mathrm{CCl} 4}^{\circ} \\
\text { (g) }\end{array}$ & $\begin{array}{c}\mathrm{M}_{\mathrm{CCl} 14}^{\mathrm{f}} \\
(\mathrm{g})\end{array}$ & $\begin{array}{l}\mathrm{M}_{\text {Calcine }}^{\circ} \\
(\mathrm{g})\end{array}$ & $\begin{array}{c}\mathrm{M}_{\text {Calcine }}^{\mathrm{f}} \\
\text { (g) }\end{array}$ \\
\hline 112 & 800 & 10 & 100 & 0 & -9.84 & 1 & 0.34 \\
\hline 113 & 800 & 15 & 100 & 0 & -13.38 & 1 & 0.19 \\
\hline 114 & 800 & 21 & 100 & 0 & -20.49 & 1 & 0.05 \\
\hline 115 & 800 & 2.5 & 100 & 0 & -2.40 & 1 & 0.83 \\
\hline 116 & 800 & 7.5 & 100 & 0 & -7.17 & 1 & 0.49 \\
\hline 117 & 800 & 12.5 & 100 & 0 & -12.13 & 1 & 0.20 \\
\hline 118 & 800 & 10 & 100 & 0 & -1.99 & 1 & 0.87 \\
\hline 119 & 800 & 20 & 100 & 0 & -3.89 & 1 & 0.75 \\
\hline 120 & 800 & 30 & 100 & 0 & -5.53 & 1 & 0.65 \\
\hline 121 & 800 & 1 & 100 & 0 & -0.62 & 1 & 0.89 \\
\hline 122 & 800 & 2 & 100 & 0 & -1.24 & 1 & 0.93 \\
\hline 123 & 800 & 4 & 100 & 0 & -2.33 & 1 & 0.85 \\
\hline 124 & 800 & 6 & 100 & 0 & -3.42 & 1 & 0.77 \\
\hline 125 & 800 & 10 & 100 & 0 & -6.31 & 1 & 0.58 \\
\hline 126 & 800 & 15 & 100 & 0 & -9.28 & 1 & 0.4 \\
\hline 127 & 800 & 20 & 100 & 0 & -11.78 & 1 & 0.27 \\
\hline 128 & 800 & 25 & 100 & 0 & -15.28 & 1 & 0.15 \\
\hline
\end{tabular}




\section{Appendix B}

Table B.1

Experimental Raw Data from Calcine Chlorination Experiments Completed in a Packed Bed Reactor

\begin{tabular}{|c|c|c|c|c|c|c|c|}
\hline 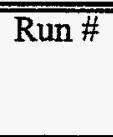 & $\overline{T_{\text {reactor }}}$ & \begin{tabular}{|c|} 
Reaction \\
Time (min
\end{tabular} & $\begin{array}{r}\text { Argon Gas } \\
\text { Flow Rate } \\
(\mathrm{ml} / \mathrm{min})\end{array}$ & $\begin{array}{c}\mathrm{M}_{\mathrm{CCl} 4}^{\circ} \\
(\mathrm{g})\end{array}$ & $\begin{array}{c}\mathrm{M}_{\mathrm{CC} 14}^{\mathrm{f}} \\
(\mathrm{g})\end{array}$ & $\begin{array}{c}\bar{M}_{\text {Calcine }} \\
(\mathrm{g})\end{array}$ & $\begin{array}{c}\overline{\mathrm{M}_{\text {Calcine }}^{\mathrm{f}}} \\
(\mathrm{g})\end{array}$ \\
\hline 1 & 600 & 3 & 351 & 0 & -0.69 & 1 & 0.90 \\
\hline 2 & 600 & 3 & 702 & 0 & -1.22 & 1 & 0.91 \\
\hline 3 & 600 & 3 & 1053 & 0 & -1.75 & 1 & 0.89 \\
\hline 4 & 600 & 3 & 1404 & 0 & -2.20 & 1 & 0.90 \\
\hline 5 & 600 & 3 & 275 & 0 & -2.09 & 1 & 0.79 \\
\hline 6 & 600 & 3 & 550 & 0 & -3.43 & 1 & 0.71 \\
\hline 7 & 600 & 3 & 825 & 0 & -3.87 & 1 & 0.75 \\
\hline 8 & 600 & 3 & 1100 & 0 & -5.54 & 1 & 0.81 \\
\hline 9 & 600 & 3 & 1375 & 0 & -8.61 & 1 & 0.75 \\
\hline 10 & 600 & 3 & 330 & 0 & -1.15 & 1 & 0.88 \\
\hline 11 & 600 & 3 & 660 & 0 & -2.28 & 1 & 0.85 \\
\hline 12 & 600 & 3 & 990 & 0 & -3.40 & 1 & 0.85 \\
\hline 13 & 600 & 3 & 1320 & 0 & -4.67 & 1 & 0.82 \\
\hline 14 & 600 & 3 & 300 & 0 & -4.43 & 1 & 0.64 \\
\hline 15 & 600 & 3 & 400 & 0 & -5.85 & 1 & 0.64 \\
\hline 16 & 600 & 3 & 600 & 0 & -8.94 & 1 & 0.65 \\
\hline 17 & 600 & 3 & 800 & 0 & -8.76 & 1 & 0.58 \\
\hline
\end{tabular}

